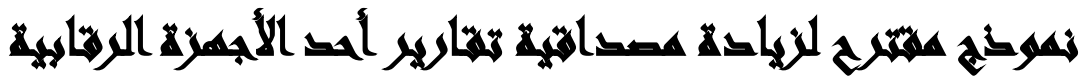

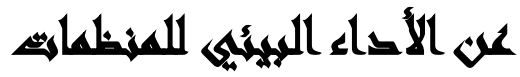

\section{[11]}

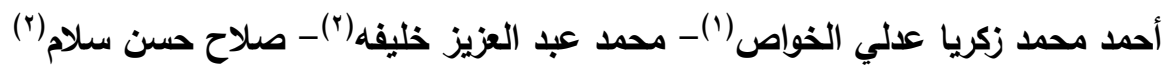

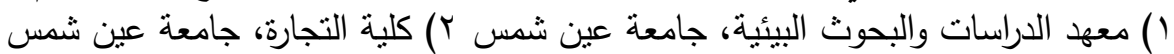

\section{المستحلم:}

قد كان لتطبيق مفاهيم التنمية المستدامة وتقييم الأثر البيئي ونظام الإدارة البيئية أثراً

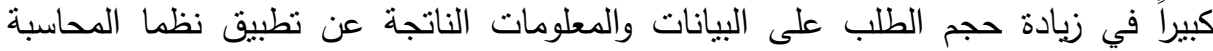

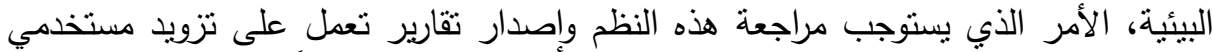

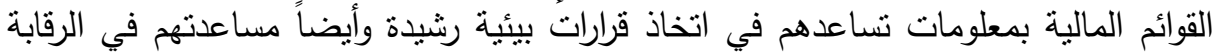

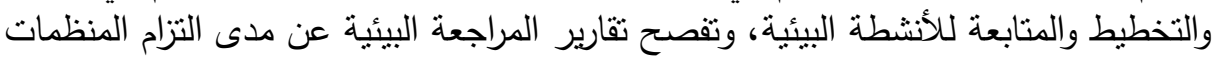

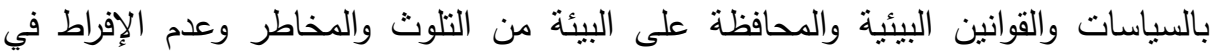

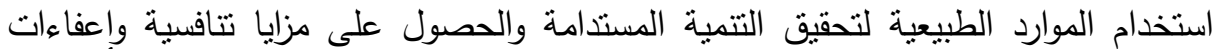
ضريبية وتجنباً لعقوبات عدم الالتزام بالقوانين البيئية.ولقد أوضحت الدارية الدراسة إن زيادة مصداقية

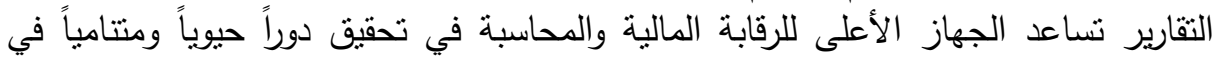
الحوكمة البيئية الفعالة لتنظيم السلوك العام والخاص نحو مزيد من المساءلة والمسئولية للحفاظ

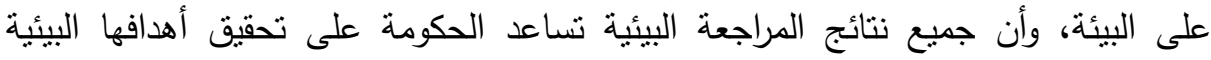
لتحقيق التتمبة المستدامة. وفي سبيل تحقيق هدف الدراسة واختبار فروضها، التئة اعتمد الباحث

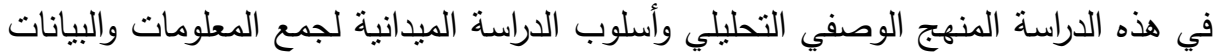

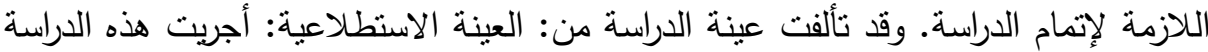

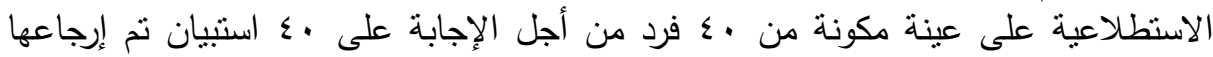

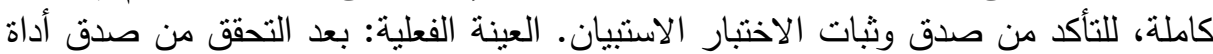

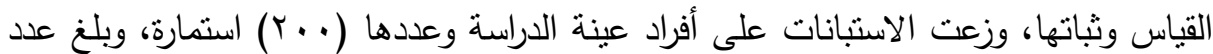

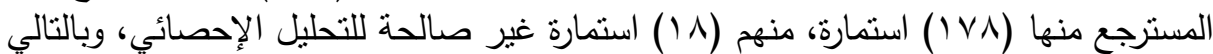

تكونت العينة الفعلية من ( • ( 1 ).

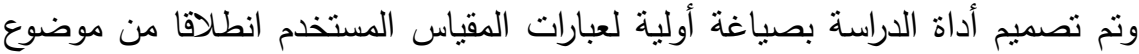

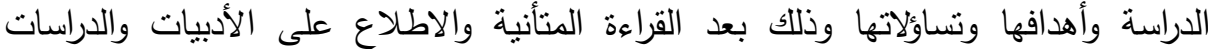

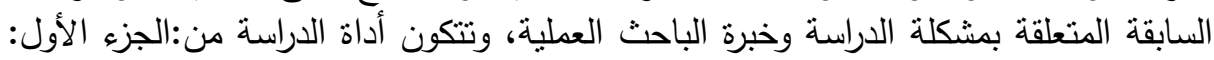

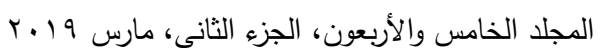


ويشمل البيانات الثخصية. الجزء الثاني: ويشمل العبارات الخاصة الإفصاح عن الأداء البيأئي

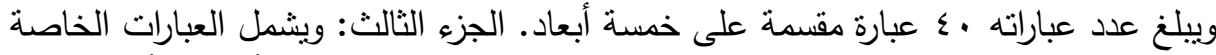

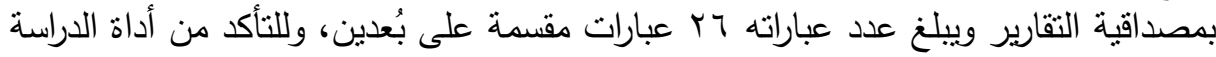

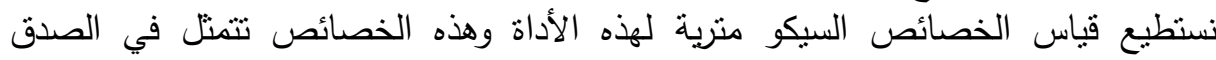

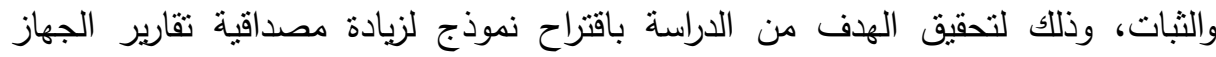

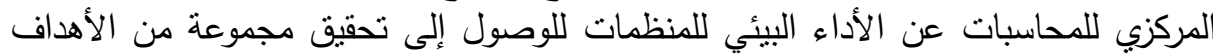

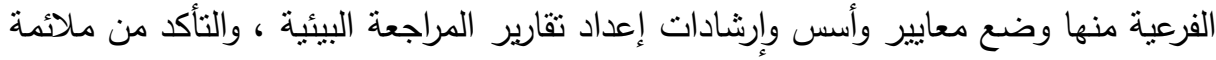

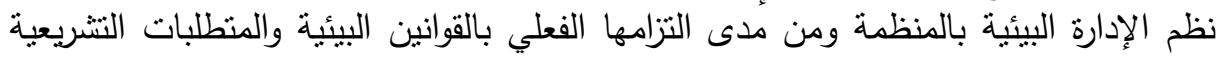

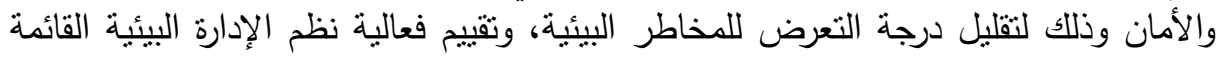

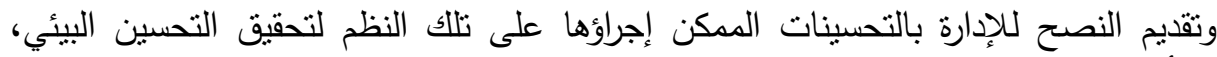

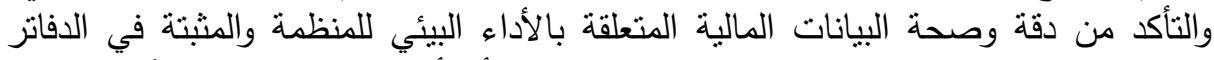

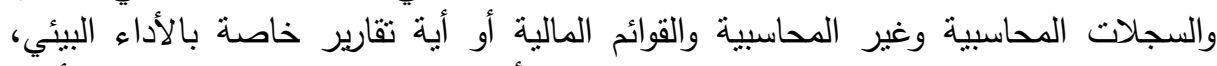
والتحقق من سلامة العرض والإفصاح عن الالنزامات أو الخسائر المحتملة الناتجة عن الألماتئة الأمور

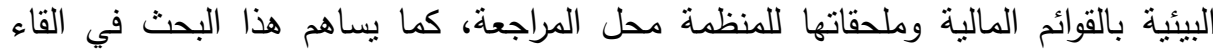

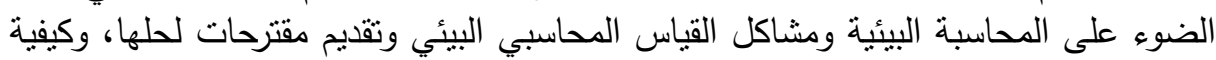

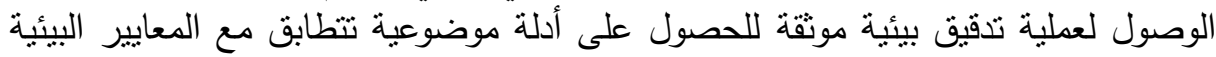
لتوفير والإفصاح عن المعلومات والبيانات المناسبة والتي تؤثنز على القوائم المالية والتقارير

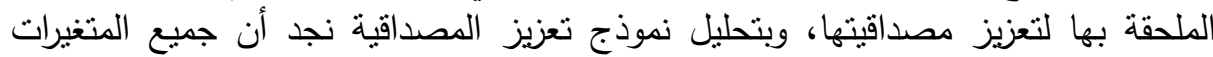
تؤدى إلى زيادة مصداقية تقارير الجهاز • وبالإضافة إلى النتائج التي توصل إليادة اليها الباحث عند تقييم الدراسات السابقة من الالتزام

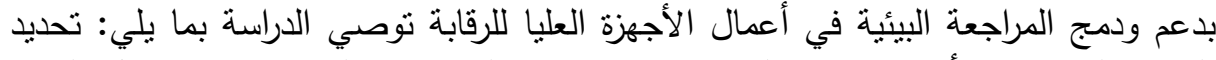

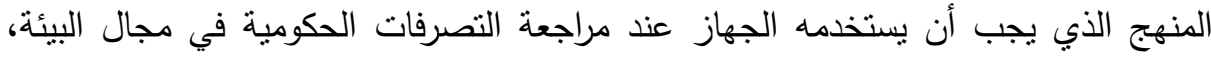

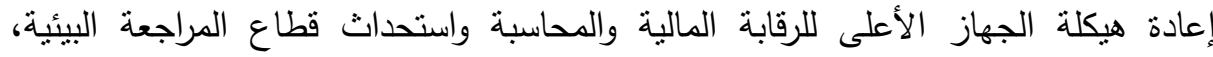

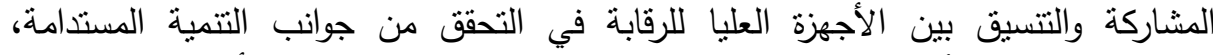

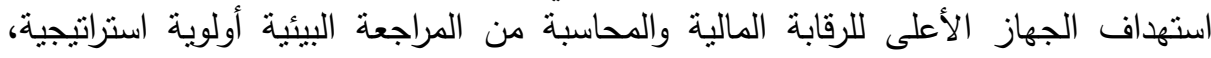
تفعيل دور الجهاز الأعلى للرقابة المالية والمحاسبة في مراجعة الاتفاقيات البيئية الدولية.

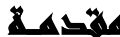

يستلزم الحفاظ على الموارد المتجددة ومنع وتخفيف ومعالجة الأضرار البيئية رقابة صارمة على تتفيذ القوانين واللوائح البيئية، ويستخدم مصطلح "المراجعة البيئية" في سياق ومئح ولئه

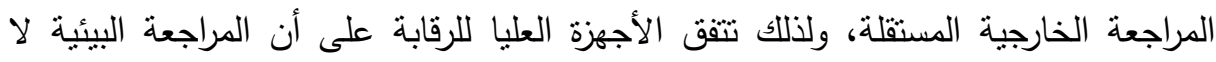
تختلف كثيراً من حيث المبدأ، عن منهج المراجعة على النحو الذي تمارسه الأجهزة العليا 
للرقابة، وإنها يمكن أن نتمل جميع أنواع المراجعة، (محمود محمد أحمد صابر، إمكانية

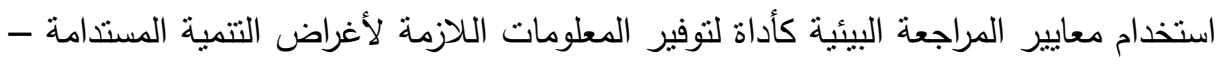
نموذج محاسبي مقترح لتقارير المراجعة البيئية-، المجلة العلمية التجارة والتمويل، كليةالتجارة

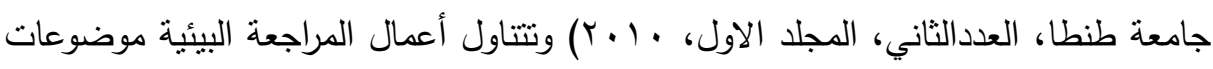

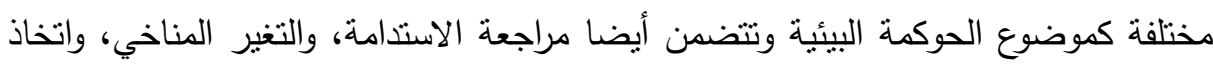

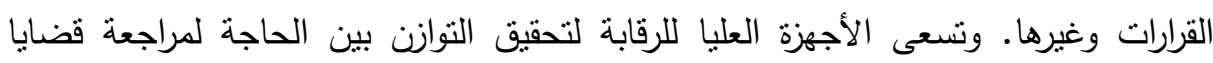

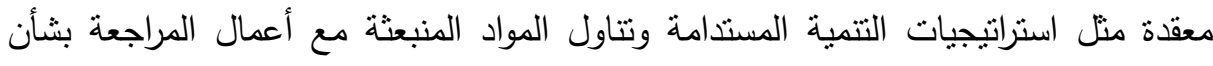

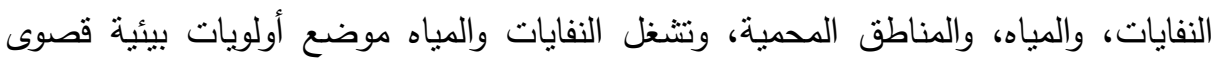

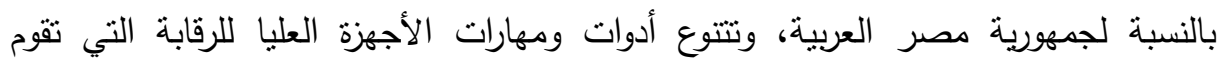
بمراجعة البيئة بنفس درجة تتوع الموضوعات التي تغطيها المراجعة البيئية نفسها. ويتعين على بلى لهيه

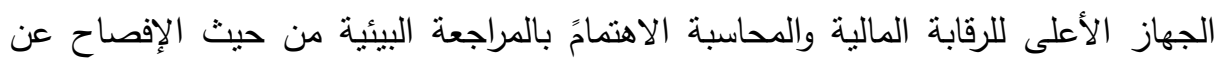

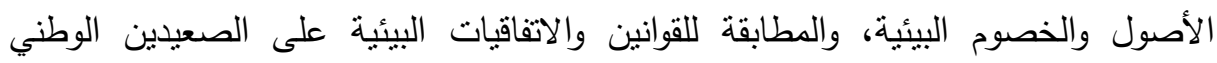

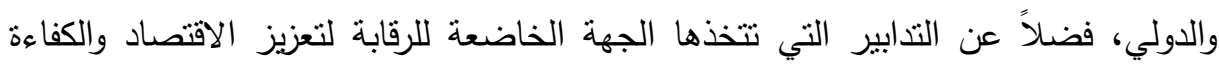
والفعالية، كما يلعب المدققون بالأجهزة الرقابية العليا دورا هاماً في معالجة المشاكل البيئية

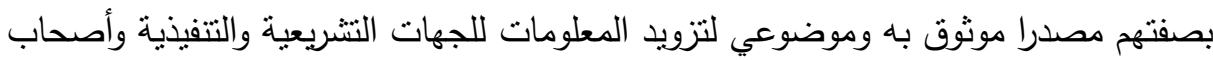
المصلحة وعلى اساسه يتم تقييم الأداء واتخاذ القرارات، ويعتبر الجهاز الأعلى للرقابة المالية

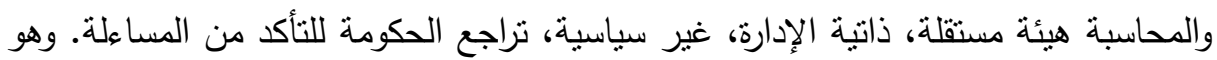
الأمين على المال العام من خلال وضعه كهيئة مستقلة تقوم بمسألة الجهاز الإداري والهيئات التابعة للدولة بكافة مستوياتها عن استخدام وادارة هذا المال العام. ولذلك يجب الثب أن تدرج

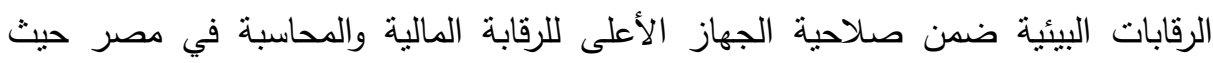
أصبحت التتمية المستدامة واقعا ملموسا يمثل تحديا أمام المحاسبة لوضع نظام محاسبي بيئي لتقديم تقارير مراجعة بيئية تفصح بمصداقية عن معلومات قانونية واستثمارية واقتصادية وبيئية مالية وغير مالية بالقوائم المالية وإيضاحاتها المتممة، وذلك لخدمة الطوائف المتعددة

$$
\text { المجلد الخامس والأربعون، الجزء الثانى، مارس } 19 \text { بـ }
$$


المستخدمة للقوائم المالية وهذا الأمر ييرز دور المراجع في إحداث التوازن البيئي وذلك من خلال زيادة مصداقية تقارير المراجعة البيئية.

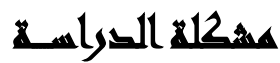

تتركز مشكلة الدراسة فيما يلي: اصبحت التتمية المستدامة اولوية استراتيجية للعديد من المنظمات وتعرف التتمية المستدامة على انها عملية التتمية التي تلبى احتباجات الاجيال الحالية دون المساس بحاجات الاجيال المستقبلية، مما يشير الى الحد من استهلالك موارد

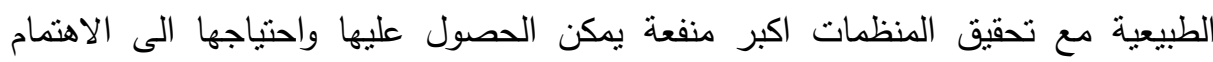
بالقضايا البيئية عند اجراء انشطتها والافصاح عنها فى تقاريرها المالية وهو ما يمكن تحقيقه من خلال تطوير الاستراتيجيات البيئية المناسبة والنهج البيئي على المدى الطويل واتخاذ

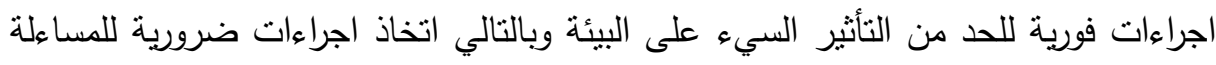

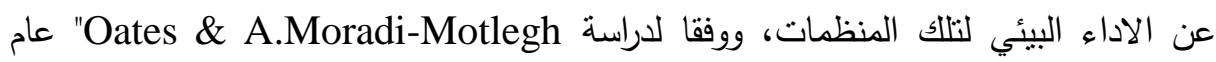
17 أب والتي تهدف الي تحديد مستوى الافصاح الاختياري عن الافصاح البيئي والاداء البيئي

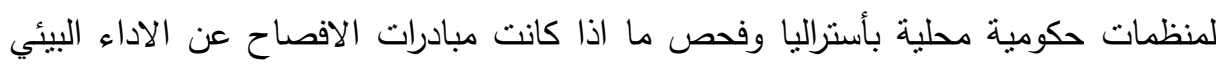

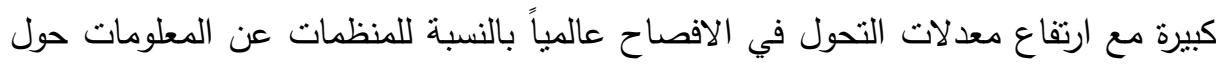
ادائها البيئي ولتحسين معدل الافصاح عن الالتزامات البيئية، وتأسيسا على ما سبق بلئ يمكن

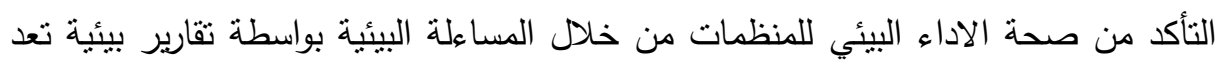
بواسطة مراقبي الحسابات لاى الاجهزة الرقابية العليا تكثف عن الممارسات البيئية الخاطئة

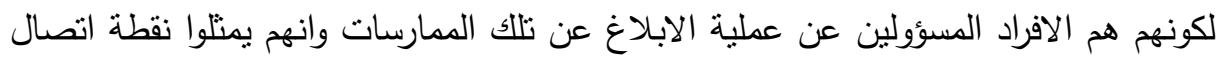

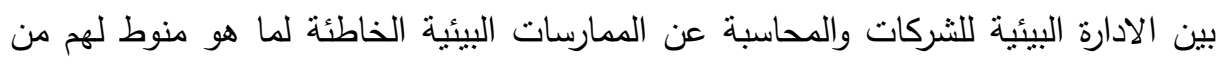
تخصصات فى مجال الرقابة على الاداء والرقابة المالية وذلك بإصدار تقارير بيئة معززة

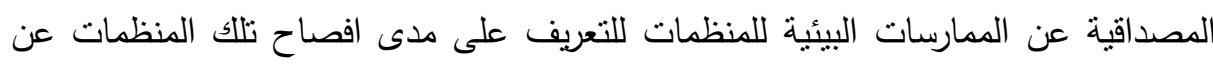

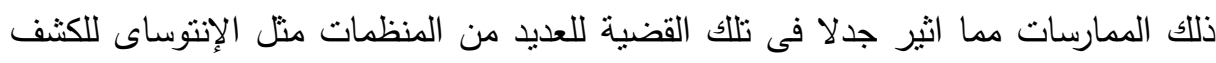

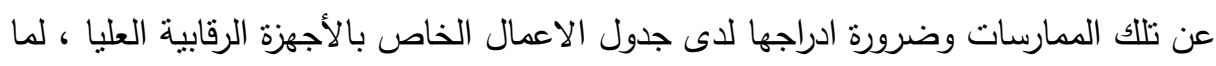

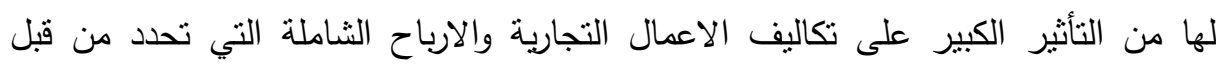

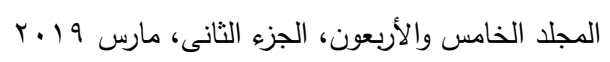


المحاسبين المهنيين، وبالرغم من اهمية المحاسبة من قبل المتخصصين بالرقابة على الاداء والرقابة المالية على الممارسات البيئية، فان التعرف على على مدى زيادة مصدافية الئية نقارير الاجهزة

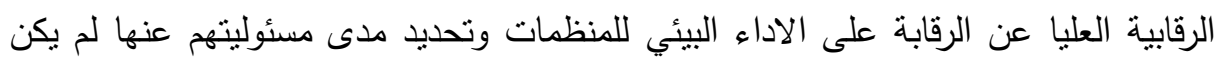

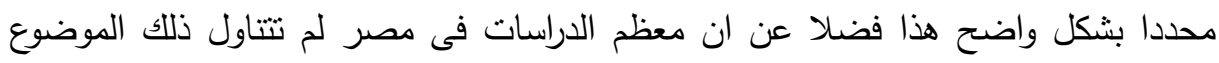
بشيء من التركيز والاهتمام.

\section{اسمئلا الهيهش}

1. ما مدى مصداقية تقارير الاجهزة الرقابية عن الرقابة على الاداءالبيئي للمنظمات؟

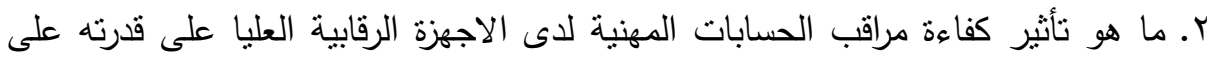

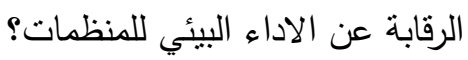

r. ما هو تأثثر خصائص الوحدة محل المراجعة على قدرة مراقب الحسابات لادى الاجهزة

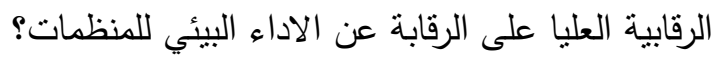

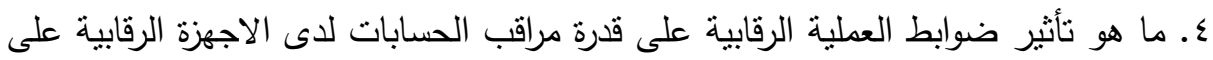

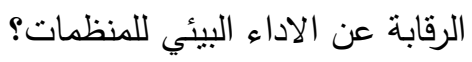

ه. ما هي الفروق جوهرية بين اراء مراقبي الاجهزة الرقابية العليا حول تحليل وتقييم والتقرير

عن الممارسات البيئية للمنظمات؟ هره

\section{أهمية الدراسـا}

الأهمية العلمية: وجود الأدوات التي تساعد على توفير معلومات جوهرية تساعد في التتمية المستدامة بشكل إيجابي ومن هذه الأدوات تقارير المراجعة البيئية، ومدى زيادة مصداقية تلكئل

الأهمية العملية: يساعد البحث على تفعيل دور الاجهزة الرقابية العليا فى الرقابة على

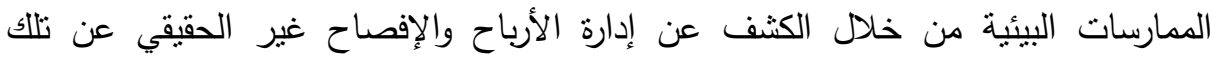


الممارسات لتجنب التكاليف السياسية التي تفرضها الحكومات على المنظمات وقياس التكاليف التي تتحملها المنظمات وبالتالي استمراريتها نتيجة اخلالها بالقوانين البيئية.

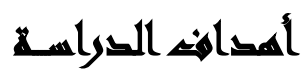

يتمثل الهدف الحالي للاراسة في قياس مصداقية تقارير الاجهزة الرقابية عن الرقابة على

الاداء البيئي للمنظمات، كما هناك اهداف فرعية تالية:

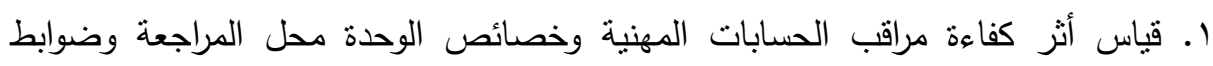
العملية الرقابية لدى الاجهزة الرقابية العليا على قدرته على الرقابة عن الاداء البيئي

للمنظمات.

r. تجديد الفروق الجوهرية بين اراء اعضاء الاجهزة الرقابية العليا حول تحليل وتقييم والتقرير عن الممارسات البيئية للمنظمات.

r. اجراء دراسة تطبيقية على الاجهزة الرقابية العليا لتعزيز مصداقية تقارير الاجهزة الرقابية

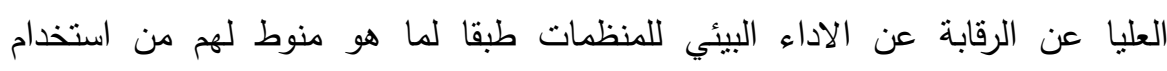
الضبطية القضائية في التقرير والابلاغ عن الممارسات البيئية الخاطئة للجهات المختصة.

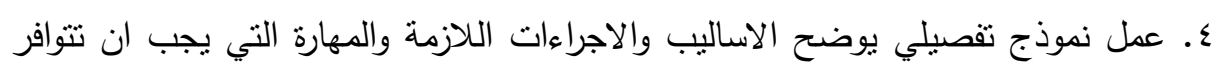
في الفاحص البيئي ومقاييس الرقابة على الاداء البيئي وذلك لقياس مصداقية الإنية تقارير الاجهزة الرقابية العليا عن الرقابة عن الاداء البيئي للمنظمات.

\section{هزوضر التراسم}

ا ـ لا نوجد علاقة جوهرية بين كفاءة مراقب الحسابات المهنية لدى الاجهزة الرقابية العليا وقدرته على الرقابة عن الاداء البيئي للمنظمات.

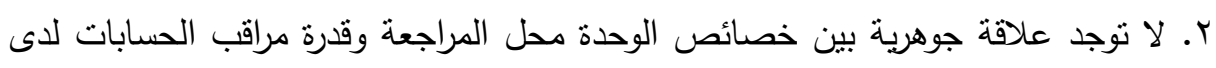

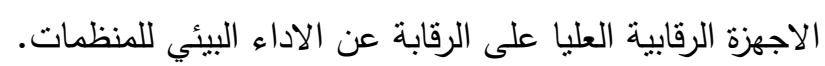

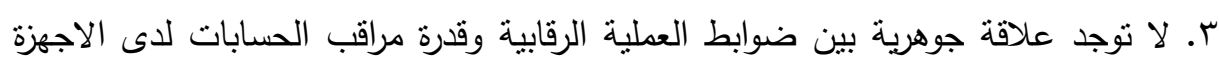
الرقابية العليا على الرقابة عن الاداء البيئي للمنظمات. 
ع. لا توجد علاقة جوهرية بين اراء اعضاء الاجهزة الرقابية العليا حول تقييم والتقرير عن

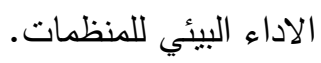

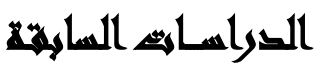

يقوم الباحثون بعرض أهم الدراسات السابقة العربية والأجنبية التي تعرضت من قريب أو

بعيد لموضوع الدراسة.

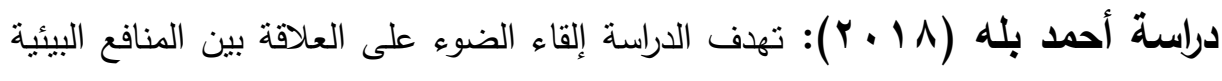

وشفافية التقارير المالية، ومعرفة العلاقة بين قياس التكاليف البيئية وشفافية التقارير المالية. وتوصلت الدراسة إلى عدة نتائج منها: الإفصاح الاختياري يؤدي إلى زيادة إقبال الأفراد على منتجات الثركة، كما يساهم الإفصاح الاختياري في تخفيض الفرص المضاعفة وتقليل

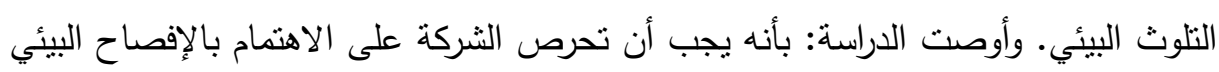
بأسلوب كمي. دراسة عبد الله محمد عبد الصادق (Y V P P): تهدف هذه الدراسة الي اعداد نموذج لاستخدام المحاسبة عن الاثر البيئي لتحسين جودة المعلومات عند اتخاذ الادارة العليا القرارات

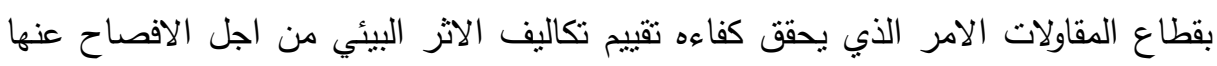
في التقارير المالية. وتوصلت الدراسة إلى عدة نتائج منها: مدى اهتمام المنشأت بقطاع الأعمال بالأثر

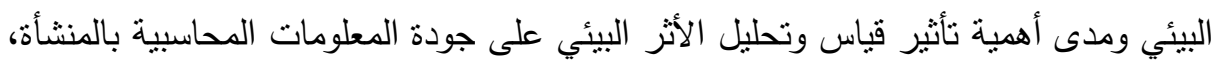
مع دعرفة المعوقات الني تقف في تطبيق عملية القياس والإفصاح عن تكاليف الأثر البيئي

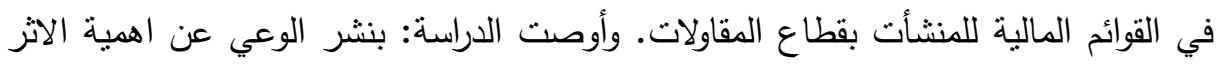

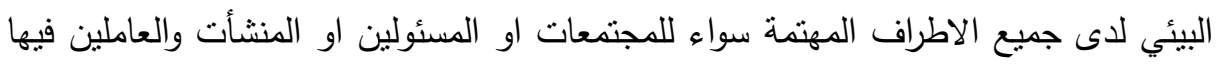
خاصة المديرين والمحاسبين. 


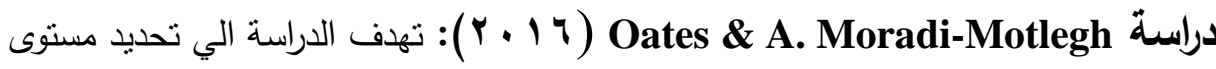

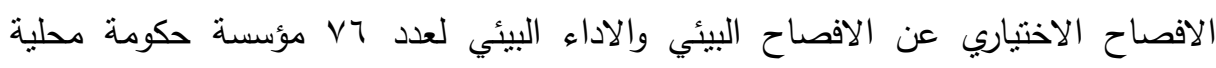
بأستراليا. وتوصلت الدراسة الى ان المؤسسات الدكومية في استراليا ذات الأداء الباء البيئي المتفوق

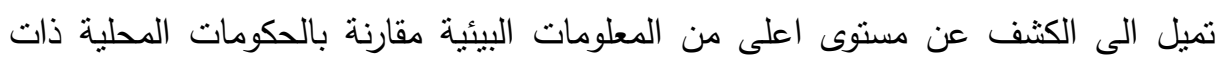

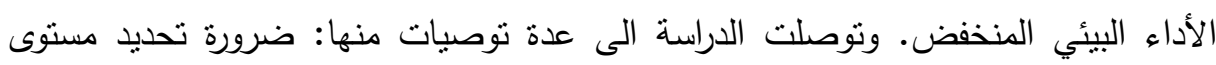

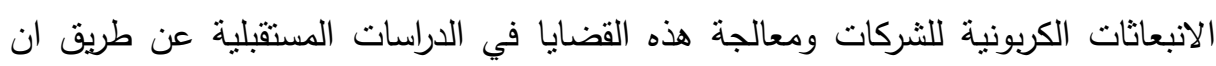

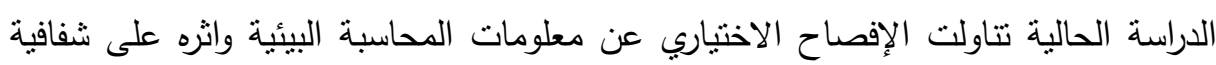

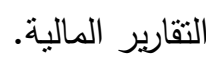

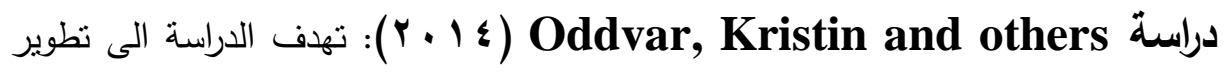

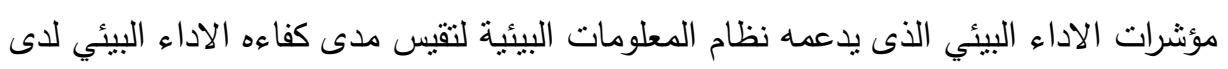

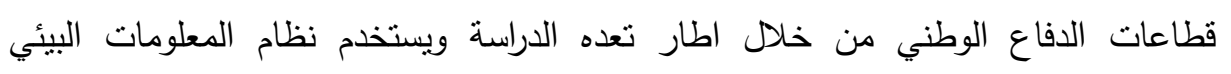

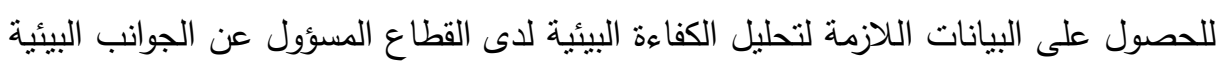

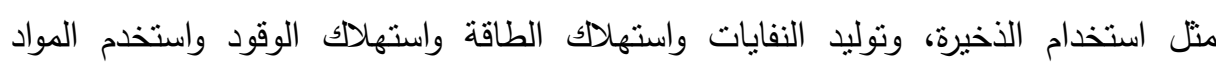

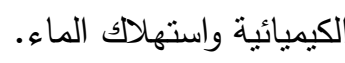

ولقد توصلت الدراسة الى ان فاعليه الإطار المقترح فى تقيم كفاءه الاداء البيئي كما ان

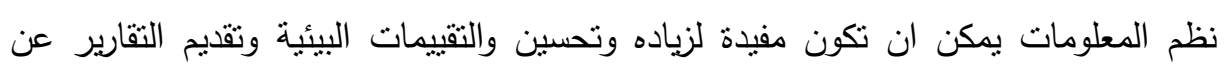

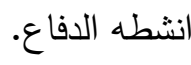

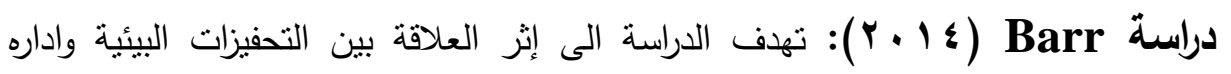

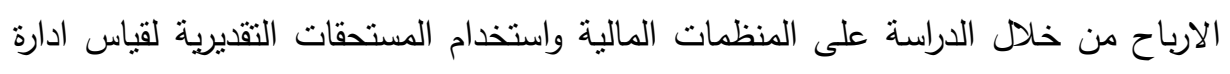
الارباح.

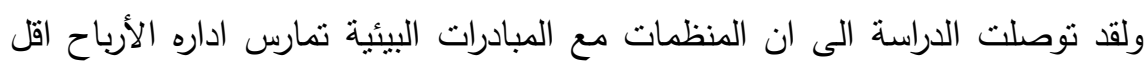

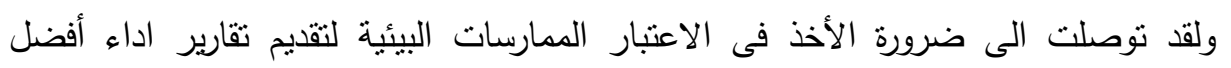

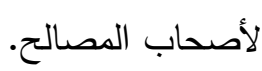


دراسة Cibran, Erwan and others (£ 1 بץ): تهذف الدراسة الى تطبق إطار التقيم الاداء البيئي للمنظمات متضمن وضع الاهداف للرقابة والحصول على المعلومات البيئية والقياس المرجعي للأداء والثقييم للنتنائج. ولقد توصلت الدراسة الى ان هناك العديد من المنظمات التي تتعدد في عدم الافصاح

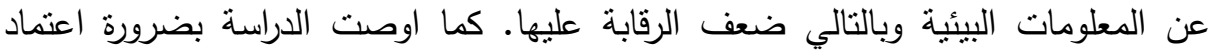
مواثيق وبروتوكولات موحده لدعم الرقابة على الممارسات البيئية للمنظمات. ويخلص البحث من خلال عرض وتحليل الدراسات السابقة الملاحظات التالية:

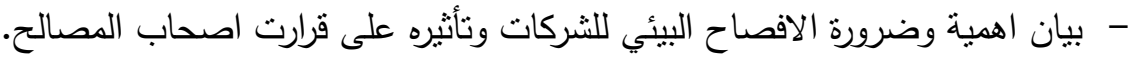
- - بيان إثر الافصاح البيئي على ممارسة ادارة الارباح.

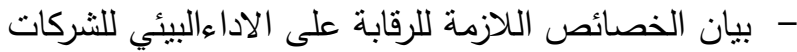
- بيان إثر تطبيق معايير الرقابة المالية على الكثف عن المانية الكارسات البيئية للثركات. - بيان اهمية اختيار التوقيت المناسب للرقابة على الممارسات البيئية للثركات. بينما لم تتناول تلك الدارسات الجوانب التالية: - قياس مصداقية نقارير الاجهزة الرقابية العليا عن الرقابة عن الاداء البيئي للمنظمات.

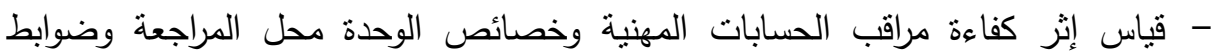
العملية الرقابية لاى الاجهزة الرقابية العليا على قدرته على الرقابة عن الاداء البيأي

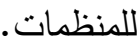
- اجراء دراسة تطبيقية على الاجهزة الرقابية العليا لقياس مصداقية تقارير الاجهزة الرقابية

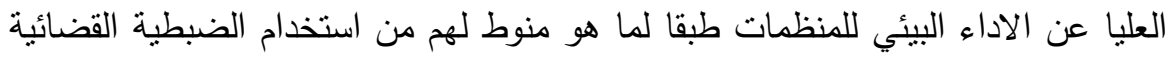

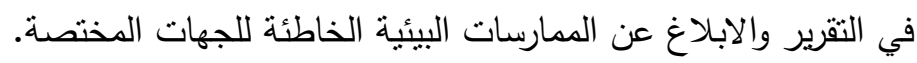

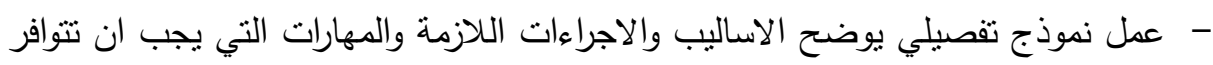

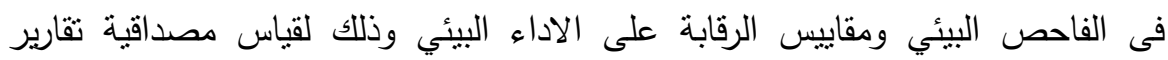
الاجهزة الرقابية العليا عن الرقابة عن الاداء البيئي للمنظمات. 


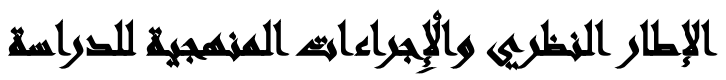

منهج الاراسة: في سبيل تحقيق هدف الدراسة واختبار فروضها، اعتمد الباحثون في هذه الدراسة المنهج الوصفي التحليلي وأسلوب الدراسة الميدانية لجمع المعلومات والبيانات اللازمة لإتمام الدراسة.

يعتمد الباحث في دراسته على الجوانب التالية: أولاً: الجانب النظري: يعتمد الباحث على ما تتضمنه الدراسات السابقة من مراجع ودوريات

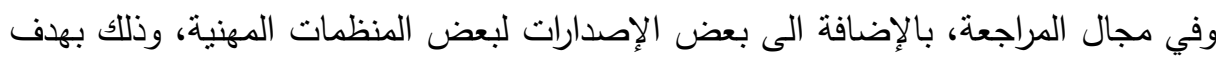

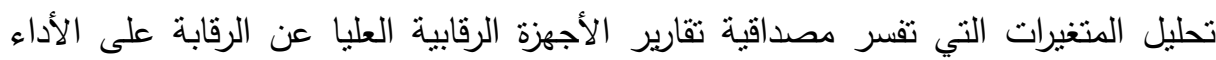
البيئي للمنظمات. ثانياً: الجانب التطبيقي: يعتمد الباحث في هذا الجانب على اجراء دراسة تطبيقية على الجهاز

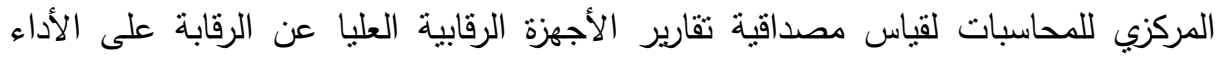
البيئي للمنظمات. مصدر البيانات فقد تم الحصول عليها من مصدرين هما: المصادر الثانوية: حيث اتجه الباحثون في معالجة الإطار النظري للإراسة إلى مصادر

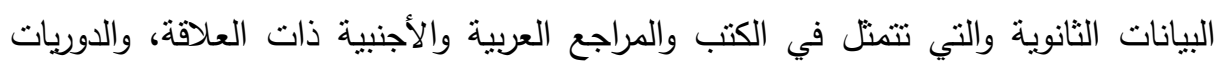
والدقالات والتقارير ، والأبحاث والدراسات السابقة التي نتاولت موضوع الدارسة، والبحث والمطالعة في مواقع الإنترنت المختلفة. المصادر الأولية: وتتمنل في جمع البيانات الأولية ميدانباً، وذلك من خلال استخدام استبيان تم تصميمه خصيصاً لهذا الغرض، ووزئ فئ على أفراد العينة لجمع البيانات المطلوبة. ميدان الدراسة: نم إجراء هذه الدراسة على السادة مدققي الحسابات بالجهاز المركزي

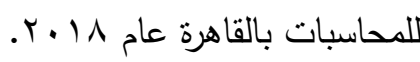
عينة الدراسةة:

أ- العينة الاستطلاعية: أجريت هذه الدراسة على عينة مكونة من •ــ فرد من أجل الإجابة على •ـ استنيان تم إرجاعها كاملة، للتأكد من صدق وثنات الاختبار الاستبيان.

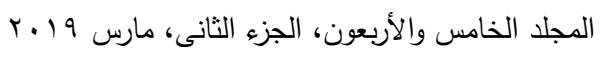


ب-أداة القياس: اعتمدنا في دراستتا الحالية على الاسنبيان كأداة من أدوات جمع البيانات

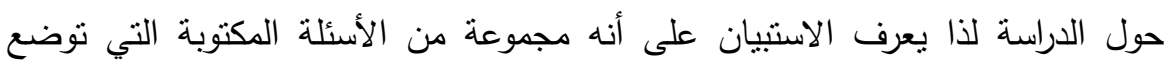
بقصد الحصول على معلومات وآراء عينة البحث حول ظاهرة أو موضوع معين ومن أهم

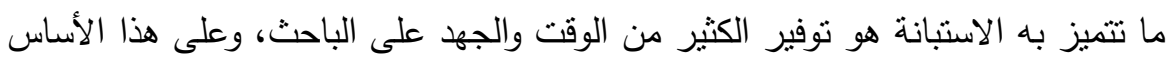

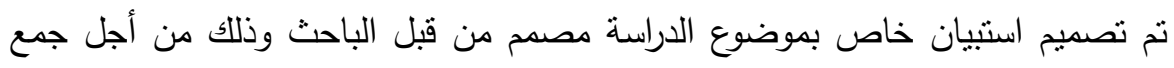

$$
\text { البيانات والمعلومات الخاصة بموضع الدراسة. }
$$

ويتكون هذا الاستبيان من محورين، المحور الأول يتضمن المتغيرات الخاصة بالإفصاح

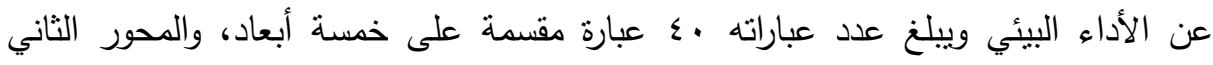

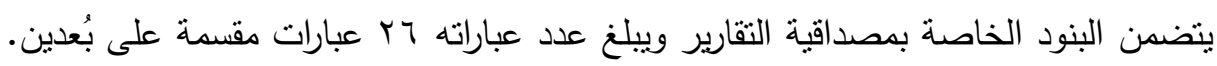

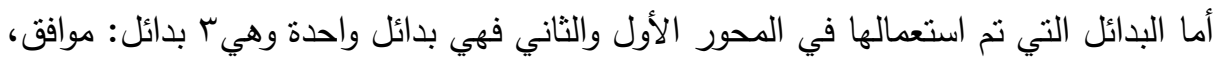
محايد، غير موافق.

ت-الخصائص السيكومترية لأداة القياس: للتأكد من أداة الدراسة المستخدمة تستطيع أن تقيس ما وضعت من أجله لتقيسه ويجب قياس الخصائص السيكو منرية لهذه الأداة وهذه الخصائص تتمثل في الصدق والثبات وسنتطرق إلى كيفية حساب كل خاصية من هاتين الخاصينتين.

ث- العينة الفعلية: بعد التحقق من صدق أداة القياس وثباتها، وزعت الاستبانات على أفراد عينة الدراسة وعددها ( . . استمارة، وبلغ عدد المسترجع منها (IVA) استمارة، منهم (1) استمارة غير صالحة للتحليل الإحصائي، وبالتالي تكونت العينة الفعلية من ( • (1 ). تصميم أداة الدراسة: قام الباحث بصياغة أولية لعبارات الاستيان انطلاقا من موضوع

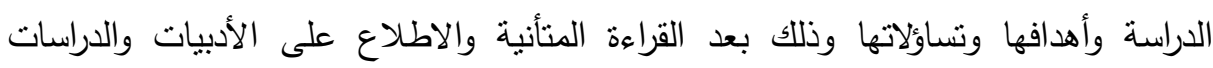
السابقة المتعلقة بمشكلة الدراسة وخبرة الباحث العملية. يحتوى الاستبيان على ثلاث أجزاء:

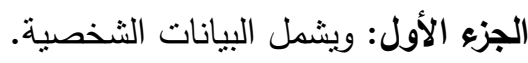


الجزء الثاني: ويشمل العبارات الخاصة الإفصاح عن الأداء البيئي وييلغ عدد عباراته .؛ عبارة مقسمة على خمسة أبعاد. الجزء الثالث: ويشمل العبارات الخاصة بمصداقية التقارير ويبلغ عدد عباراته بr عبارات مقسمة على بُعدين. وقد نم قياس استجابات أفراد العينة لفقرات الاستبيان طبقا لـقياس ليكرت الثلاثي (وافق،

$$
\text { محايد، غير موافق). }
$$

وقا تم حساب مستوي الأهمية وفقاً للمعادلة التالية:

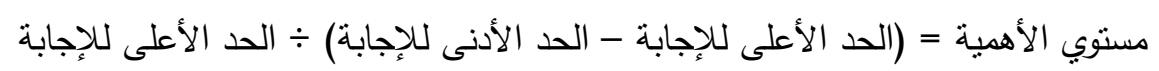
مستوي الأهمية = (r - (1) -

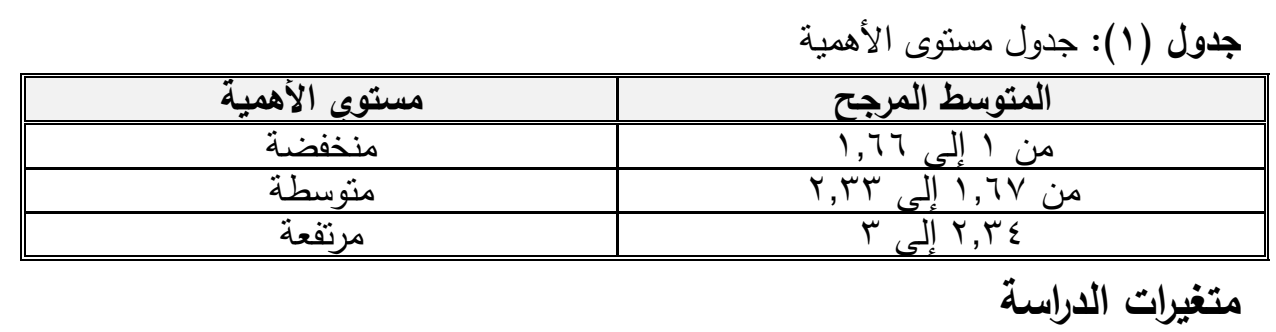
المتغير المستقل: الإفصاح عن الأداء البيئي. المتغير التابع: مصداقية التقارير • صدق وثبات أداة الدراسة: ويشمل وصف أداة الدراسة علي صدق الاتساق الظاهري وثبات وصدق الاتساق الداخلي لأداة الدراسة وذلك على النحو التالي:

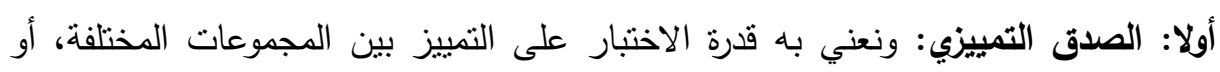
حتى الأفراد التي تقع درجاتهم على طرفي المنحنى. ثانياً: صدق الاتساق الاخلي: يقصد بصدق الاتساق الداخلي مدى اتساق كل عبارة من

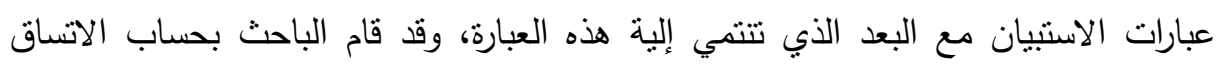
الداخلي للاستبيان وذلك من خلال حساب معاملات الارنباط بين كل عبارة من عبارات أبعاد الاستبيان والدرجة الكلية للبعد نفسه. 
ثالثاً: الصدق البنائي: يعتبر الصدق البنائي أحد مقاييس صدق الأداة الذي يقيس مدى تحقق الأهداف التي تريد الأداة الوصول إليها، ويبين مدي ارتباط كل بعد من أبعاد الدراسة بالدرجة الكلية لعبارات الابعاد.

رابعاً: ثبات الاستبيان: يقصد بثبات الاستبيان أن يعطي هذه الاستبيان نفس النتيجة لو نم

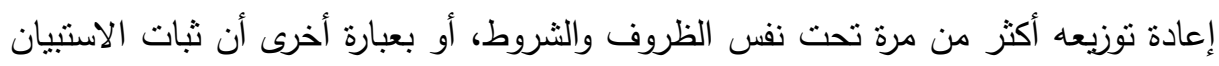

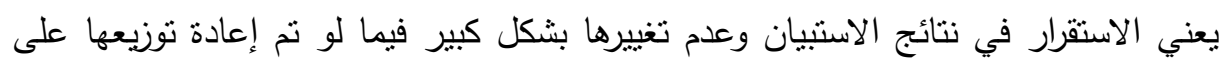
أفراد العينة عدة مرات خلال فترات زمنية معينة.

وقد قام الباحث من التحقق من صدق الاتساق الداخلي والصدق البنائي وثبات الاستبيان

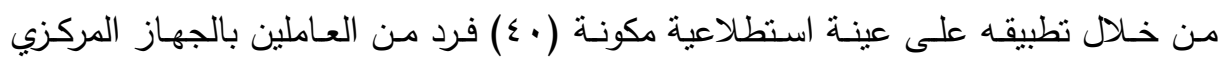
للمحاسبات.

وقد أثتتت الدراسة الإحصائية التى قام بها الباحث على عينة المدققين الرقابيين من كافة

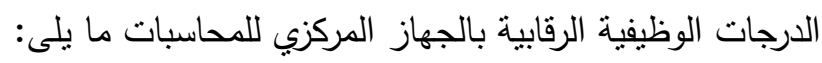
أولاً: نتائج التحليل الوصفي للمتفير المستقل (الإفصاح عن الأداء البيئي):

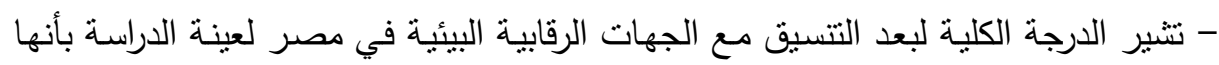

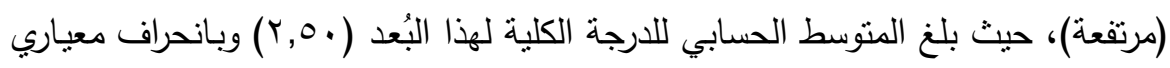

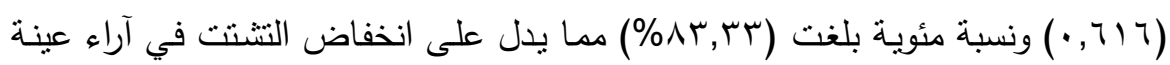
الدراسة وثقارب الآراء.

- تنشير الدرجـة الكلية الواردة لبُعد متطلبـات نموذج مصداقية التقارير الرقابية البيئية لعينـة

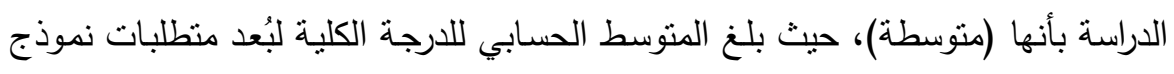

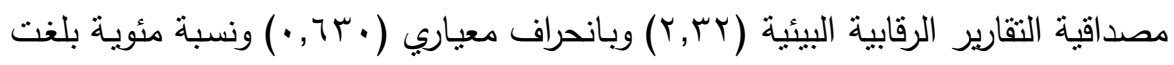
(\%VV,rr)

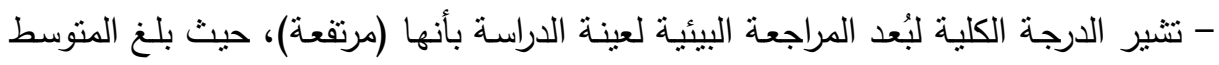

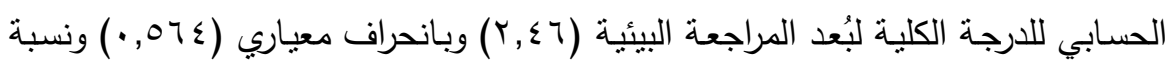
مئوية بلغت (r^\%) مما يدل على انخفاض التتتت في آراء عينة الدراسة وتقارب الآراء.

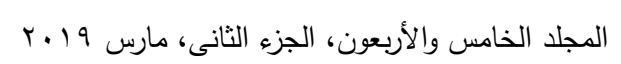


- ونتير الدرجة الكلية لُُعد الإفصاح البيئي لعينة الدراسة بأنها (مرتفعة)، حيث بلغ المتوسط

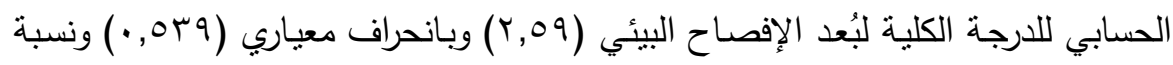

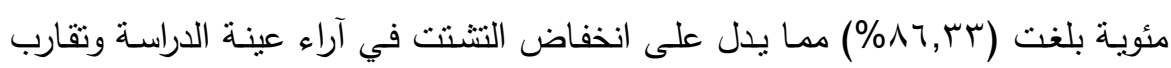
الآراء.

- تشير الدرجة الكلية لبُعد حوكمة الإداء البيئي للمنظمات لتحقيق الافصـاح الدحاسبي لعينة

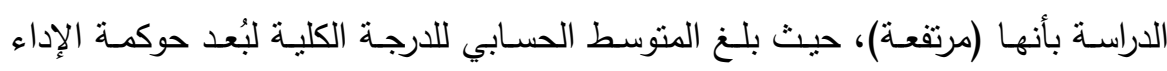

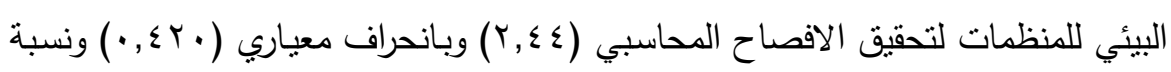

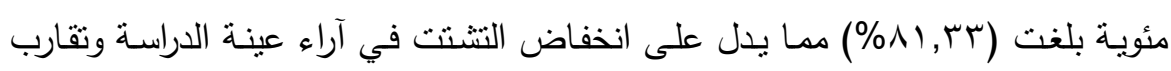

\section{ثنانياً: نتائج التحليل الوصفي للمتفير التابع (مصداقية التقارير):}

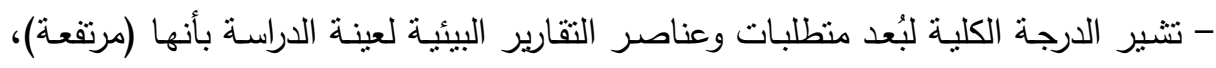

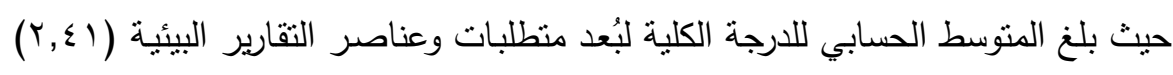

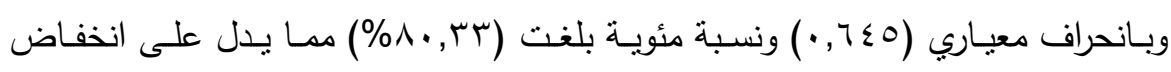
النتنت في آراء عينة الدراسة وتقارب الآراء.

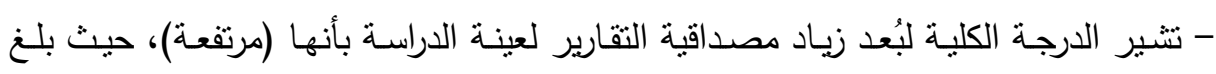

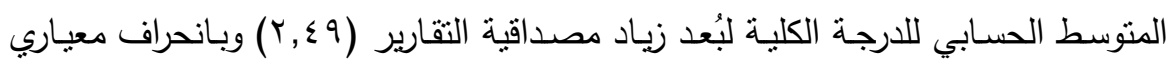

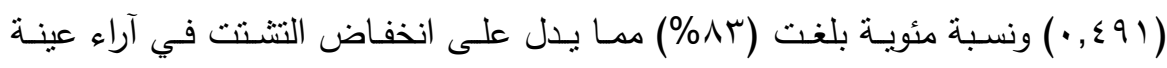

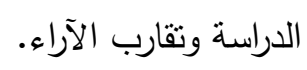

ثالثا: اختبار صحة الفرضيات المتعلقة بوجود علاقة تأثير معنوية بين أبعاد الدراسة:

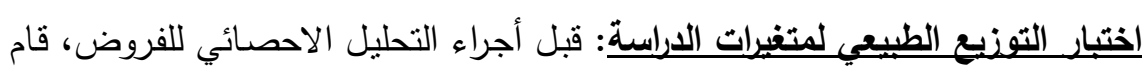

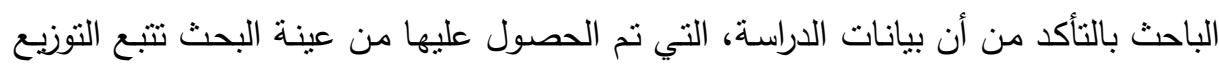
الطبيعي أم لا، وهو اختبـار ضـروري في حالـة الفرضيات، لان معظم الاختبـارات المعمليـة

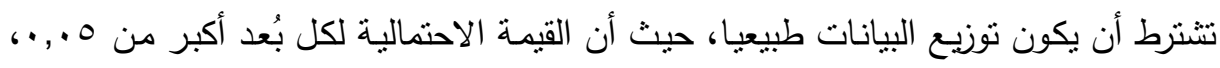
وهذا يدل على أن البيانات تتبع التوزيع الطبيعي ويجب استخدام الاختبارات المعملية. 
تحليل فروض الدراسـةة: تتحدد مقاصد هذا البند في اختبار صحة الفرضيات المتعلقة بوجود علاقة تأثثر معنوية بين أبعاد الدراسـة، وقد استخدم الباحث طريقة الانحدار الخطي

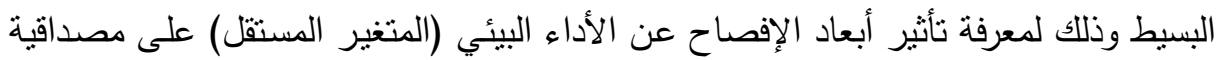
التقارير (المتغير التابع). الفرضية الرئيسية: يوجد علاقة أثر ذات دلالة إحصائية للإفصساح عن الأداء البيئي على مصداقية التقارير • وينبثق منها الفروض الفرعية الأثية: الفرض الفرعي الأول: توجد علاقة أثز ذات دلالة احصائية لبُعد التتسيق مع الجهات الرقابية البيئية على مصداقية التقارير • وللتحقق من صحة هذا الفرض قام الباحث باستخدام الانحدار الخطي البسيط. إذ أظهرت نتائج التحليل الإحصائي وجود تأثير ذو دلالة إحصائية لبُعد التتسيق مـع

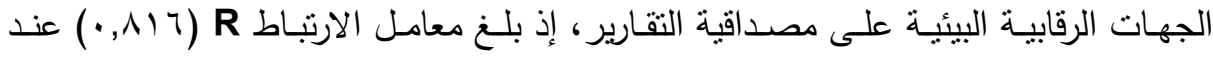

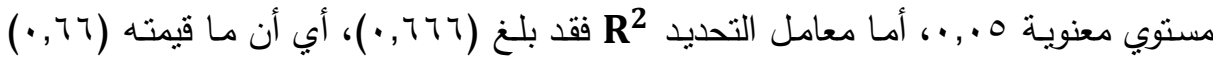
من التغير في مصداقية التقارير ناتج عن التغير في بُعد التنسيق مع الجهات الرقابية البيئية،

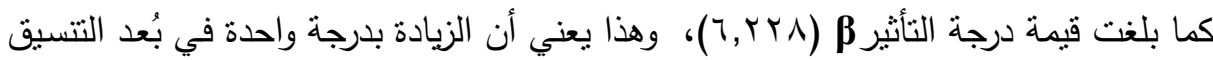

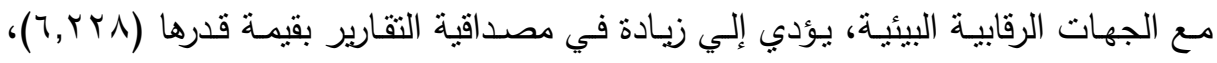

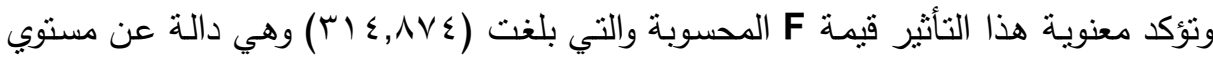

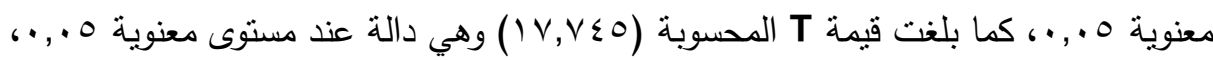
وهذا يؤكد صحة قبول الفرض الذي ينص على: توجد علاقة أثز ذات دلالة احصائية

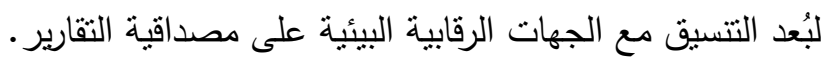
الفرض الفرعي الثاني: إذ أظهرت نتائج التحليل الإحصائي وجود نأثير ذو دلالة إحصائية

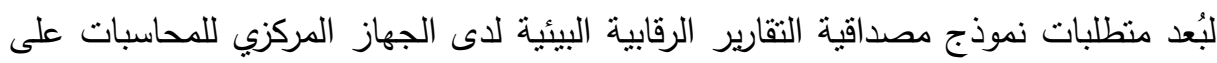

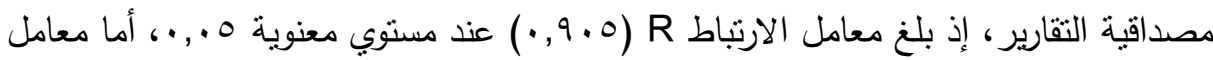

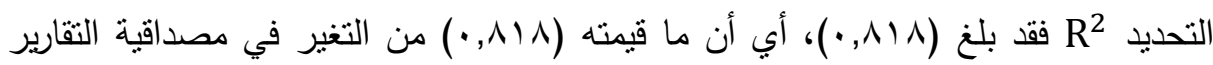
ناتج عن التغير في بُعد منطلبات نموذج مصداقية التقارير الرقابية البيئية لدى الجهاز

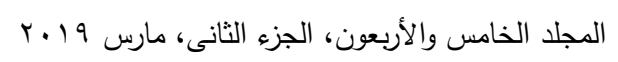




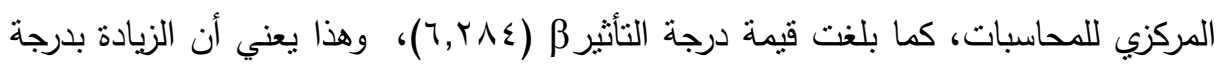

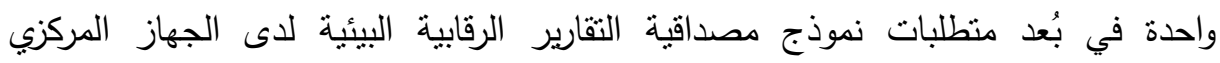

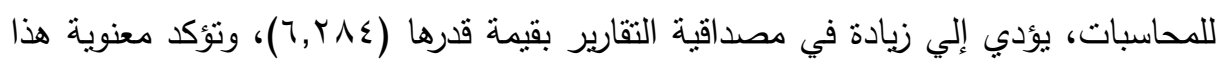

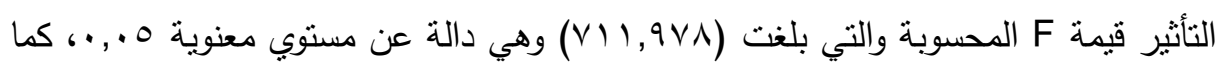

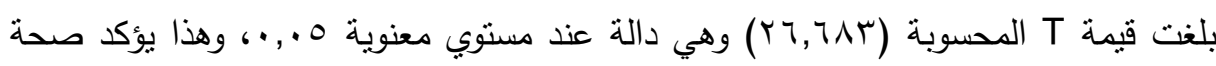

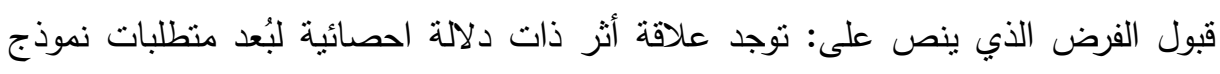

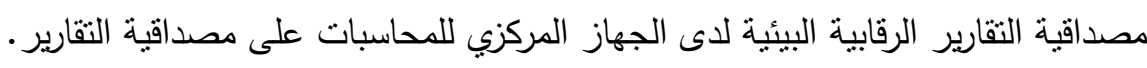

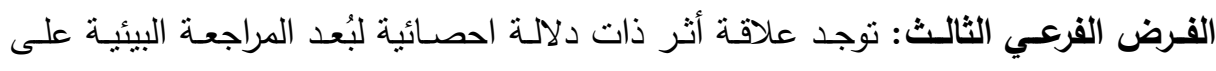
مصداقية التقارير • وللتحقق من صحة هذا الفرض قام الباحث باستخدام الانحدار الخطي البسيط: إذ

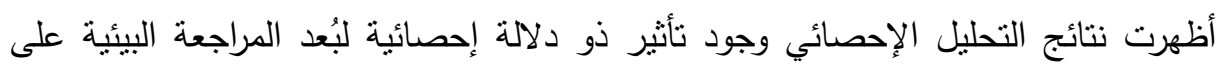

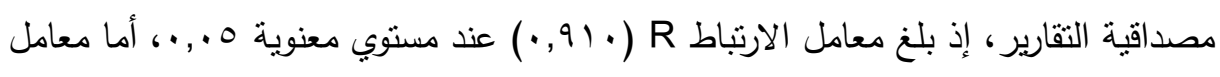

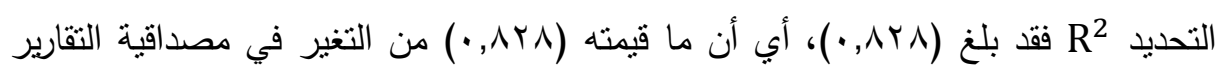

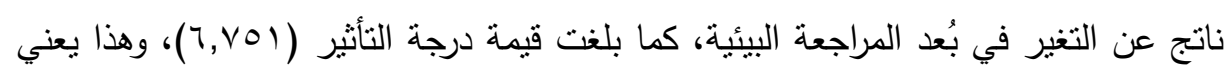

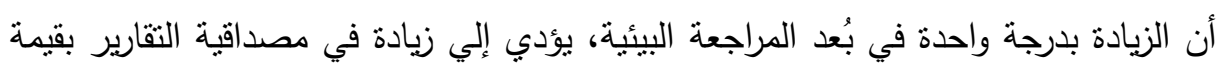

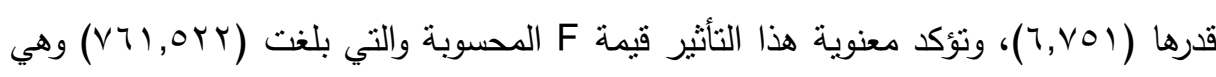

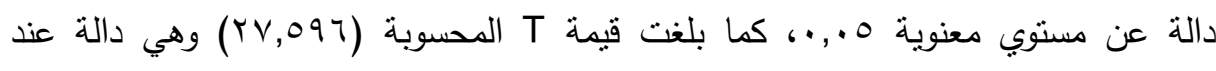

$$
\text { مستوي معنوية } 0 \text {.,. }
$$

وهذا يؤكد صحة قبول الفرض الذي ينص علي: توجد علاقة أثز ذات دلالة احصائية

$$
\text { لبُعد المراجعة البيئية على مصداقية التقارير • }
$$

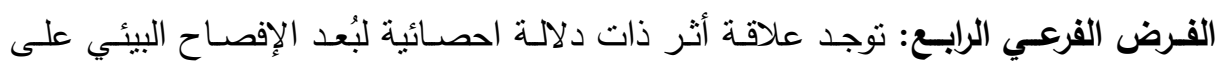

مصداقية التقارير •

وللتحقق من صحة هذا الفرض قام الباحث باستخدام الانحدار الخطي البسيط: إذ

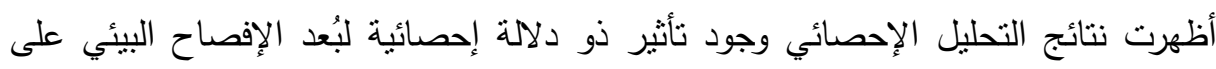

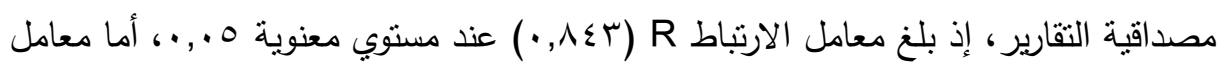

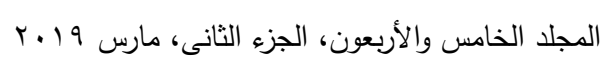




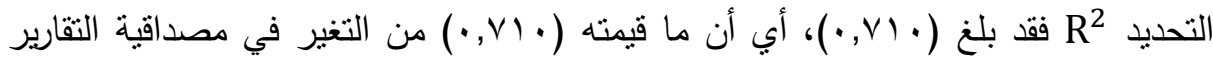

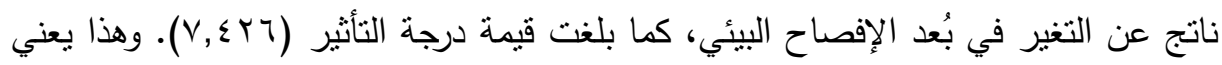

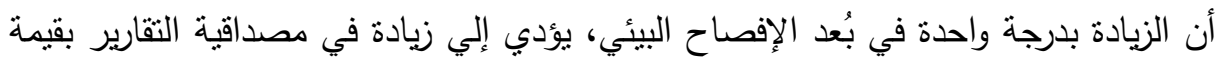

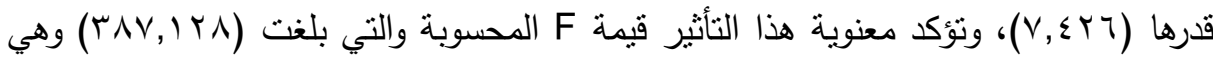

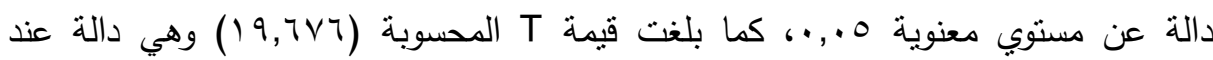
مستوي معنوية 0 ., .

وهذا يؤكد صحة قبول الفرض الذي ينص على: توجد علاقة أثز ذات دلالة احصائية

لبُعد الإفصاح البيئي على مصداقية التقارير • البول

الفرض الفرعي الخـامس: توجد علاقة أثر ذات دلالـة احصـائية لبُعد حوكمـة الإداء البيئي

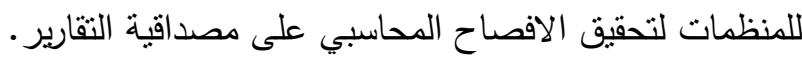

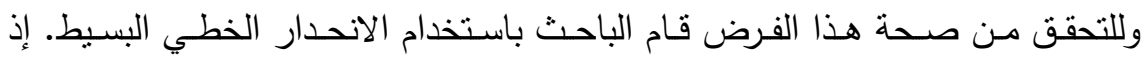

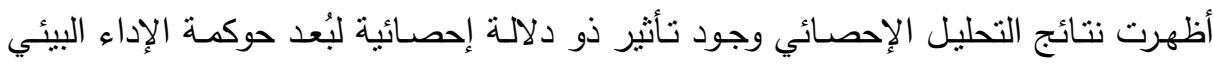

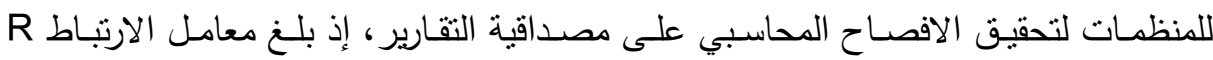

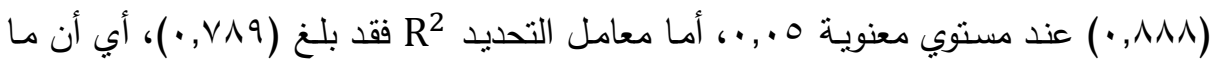
قيمته (V^9, · · ) من التغير في مصداقية التقارير ناتج عن التغير في بُعد حوكمة الإداء البيئي

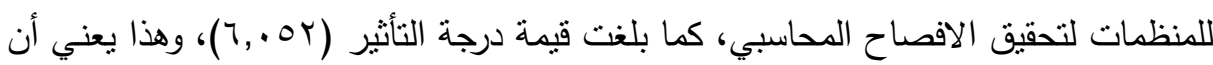

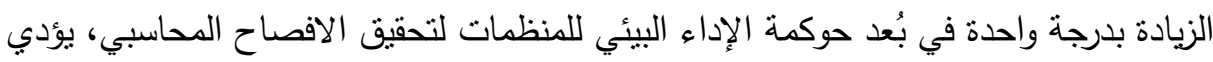

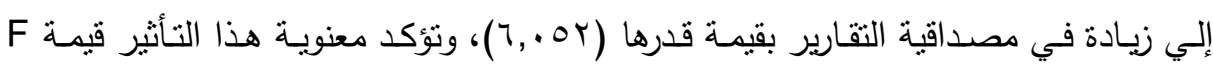

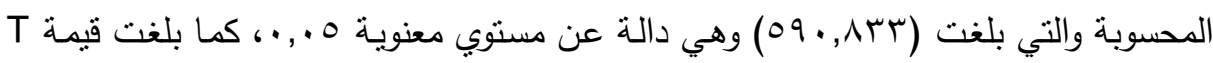

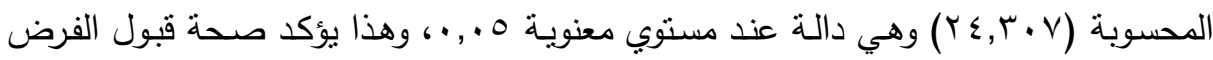

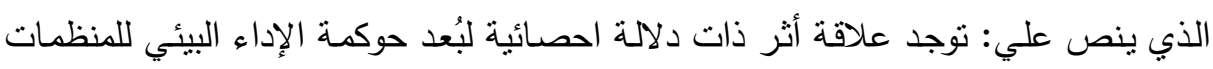

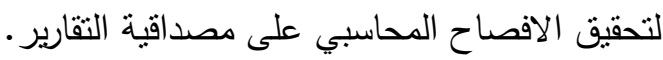
الفرضية الرئيسية الاولي: توجد علاقة أثز ذات دلالة إحصائية للإفصاح عن الأداء البيئي على مصداقية التقارير: وللتحقق من صحة هذا الفرض قام الباحث باستخدام أسلوب تحليل

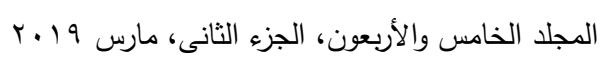


الانحدار المتعدد لاختبار هذه الفرضية، وقبل إجراء اختبار الانحدار المتعدد، قام الباحث

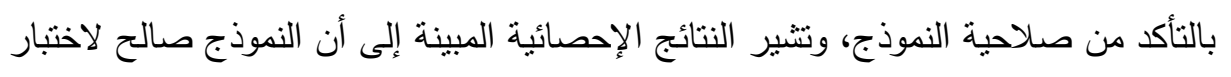

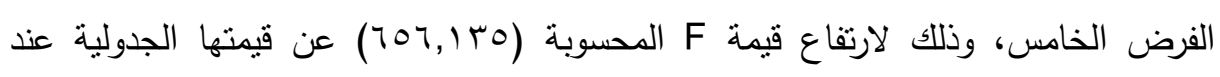

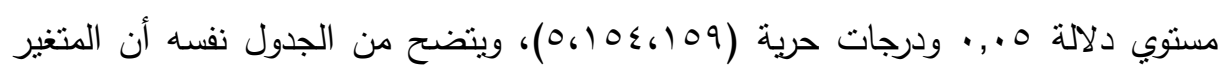

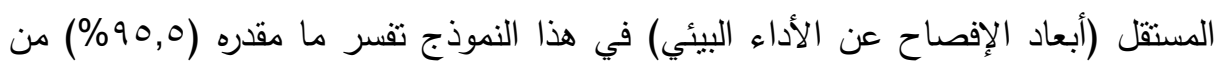
التغير الحادث في المتغير التابع (مصداقية التقارير)، وذللك استتاداً إلى قيمة معامل التهادئ التحديد التارير) = R2 (900, •) وهي قدرة تقسيرية مرتفعة لتقسير التباين في المتغير التابع (مصداقية التقارير ). وبناءً على ثبات صلاحية النموذج فقد نم اختبار الفرض الخامس باستخدام تحليل

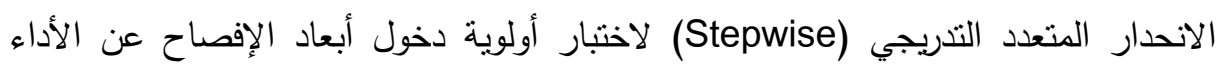

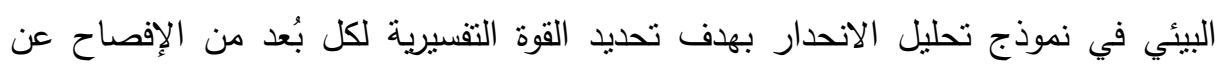
الأداء البيئي في المتغير التابع (مصداقية النقارير ) وهذا يبين دخول أبعاد الإفصاح عن الأداء البيئي (المتغير المستقل) في معادلة الانحدار، أن بُعد (المراجعة البيئية) قد احتل المركز

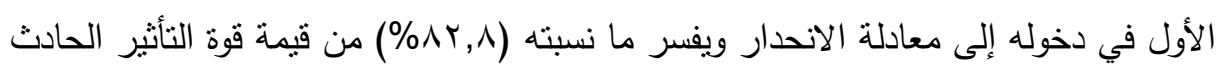

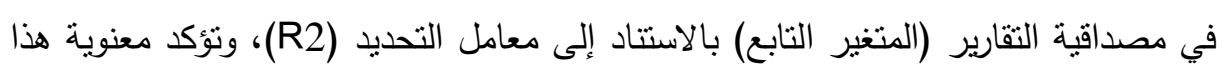

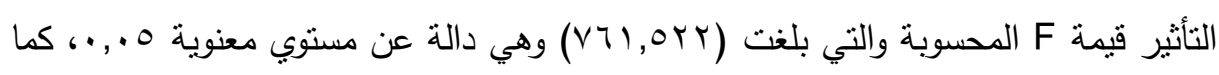

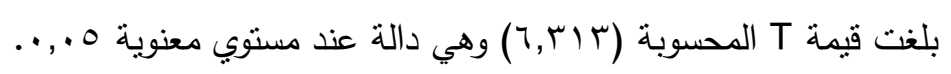

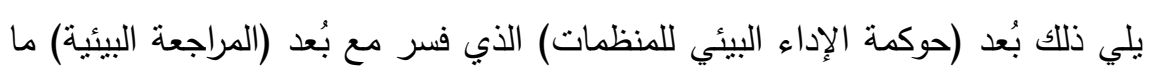
نسبته (rq\%) من قيمة قوة التأثير الحادث في مصداقية التقارير (المتغير التابع) بالاستتاد

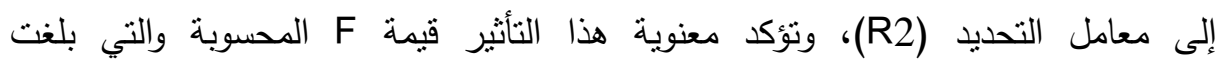

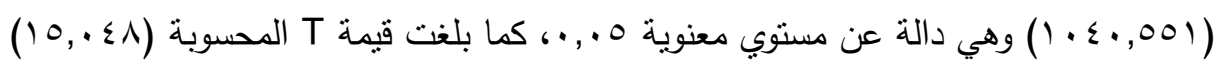

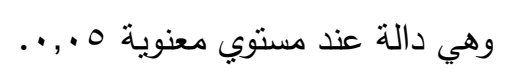

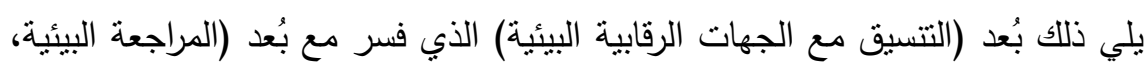

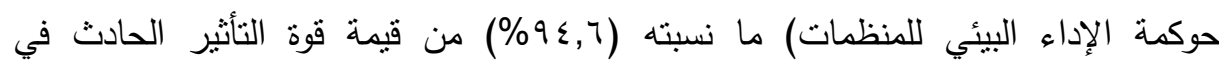

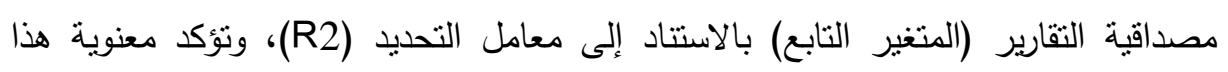

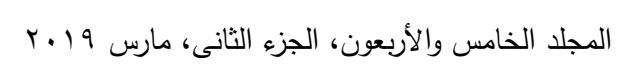




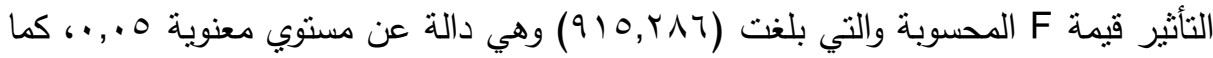

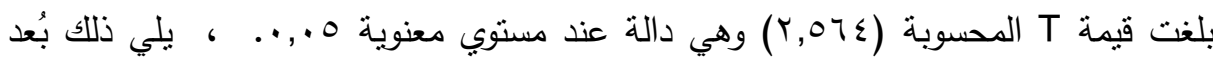
(منطلبات نموذج مصداقية التقارير الرقابية) الذي فسر مع بُعد (المراجعة البيئية،حوكمة الإداء

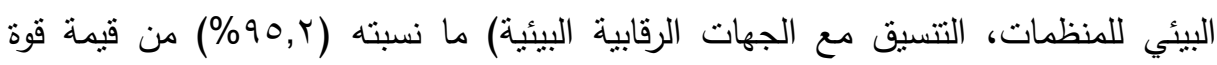

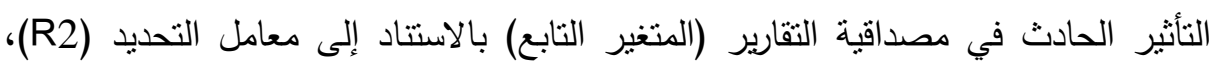

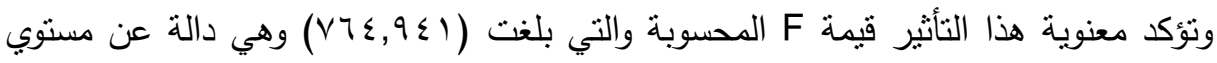

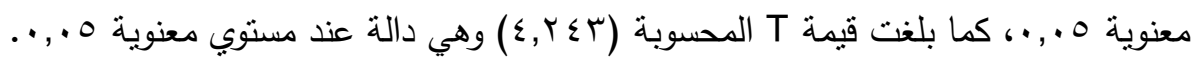
يلي ذلك بُعد (متطلبات نموذج مصداقية التقارير الرقابية) الذي فسر مع بع بُعد (المراجعة

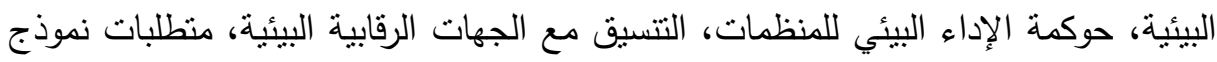

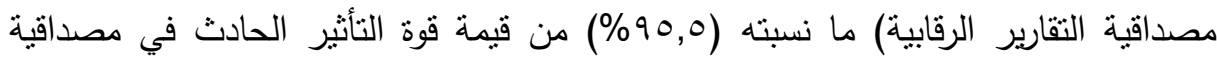

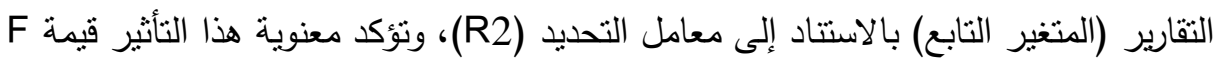

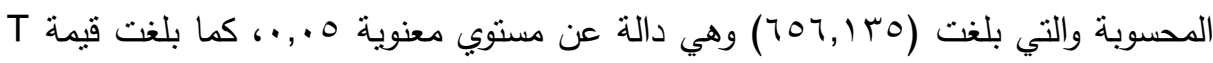

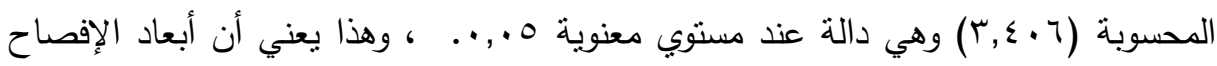
عن الأداء البيئي مجتمعة معا، تدل على أن التغير الحادث في مصداقية التقارير (المتغير

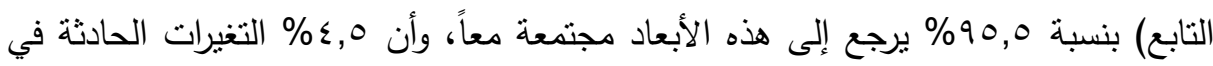
مصداقية التقارير (المتغير التابع) نرجع إلى الخطأ العشوائي أو عوامل أخري.

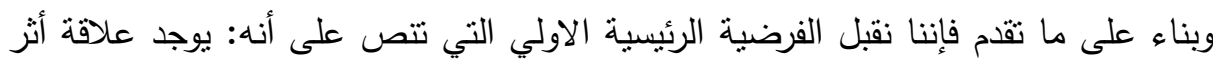

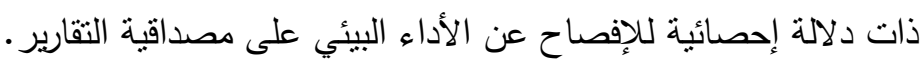
الفرضية الرئيسية الثانية: توجد علاقة معنوية ذات دلالة إحصائية لأبعاد الإفصاح عن الألئية الأداء البيئي ومصداقية التقارير • ولتحقق من هذا الفرض، قام الباحث بحساب معامل ارتباط بيرسون. ا ـ توجد علاقة ارتباط معنوية بين بُعد (التنسيق مع الجهات الرقابية البيئية) مصداقية التقارير

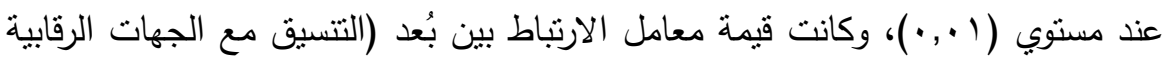

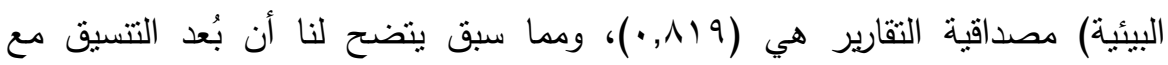

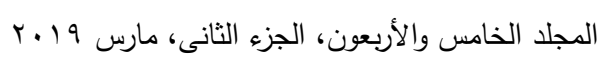


الجهات الرقابية البيئية يرتبط ارتباطًا طرديًا بمصداقية التقارير، أي أنه كلما زاد بُعد

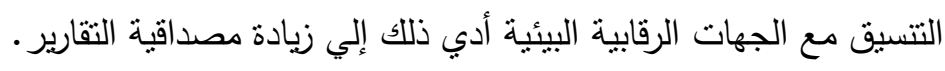

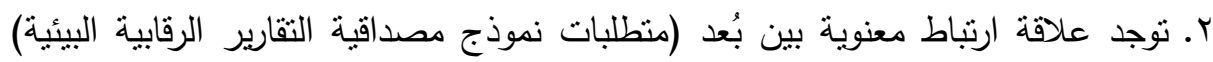

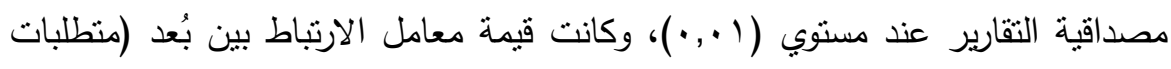

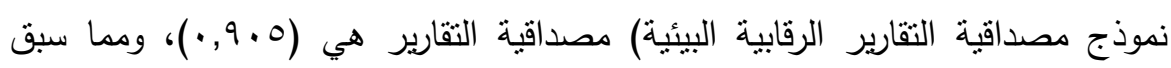

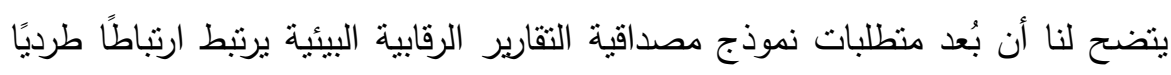

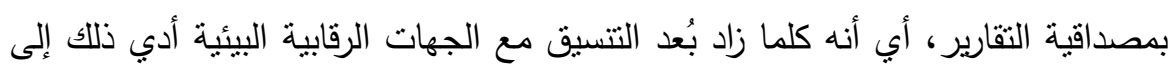
زيادة مصداقية التقارير .

r. توجد علاقة ارتباط معنوية بين بُعد (المراجعة البيئية) مصداقية الثقارير عند مستوي

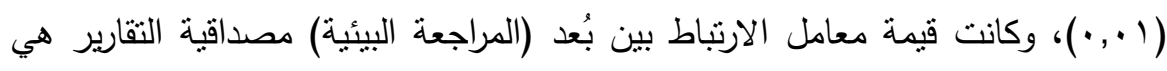

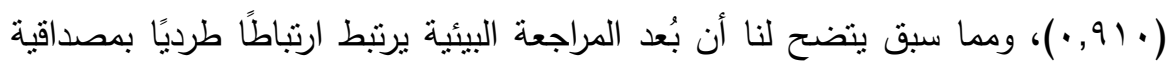

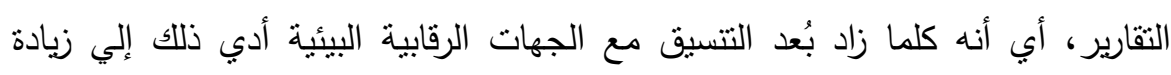

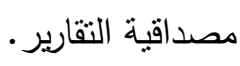

ع. توجد علاقة ارتباط معنوية بين بُعد (الإفصاح البيئي) مصداقية النقارير عند مستوي

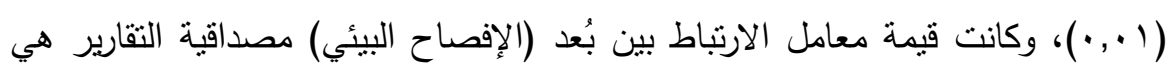

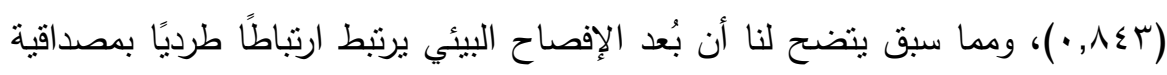

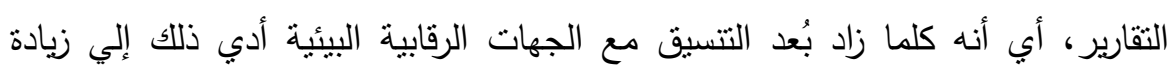
مصداقية الثقارير . 0. توجد علاقة ارتباط معنوية بين بُعد (حوكمة الإداء البيئي للمنظمات لتحقيق الافصاح

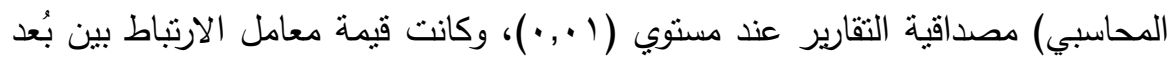

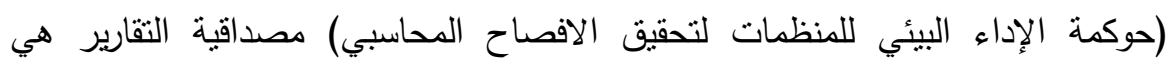

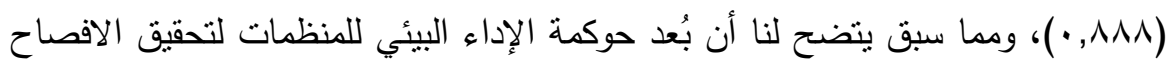

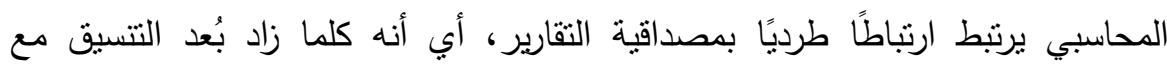
الجهات الرقابية البيئية أدي ذلك إلي زيادة مصداقية التقارير . 
الفرضية الرئيسية الثالثة: لا يوجد فروق ذات دلالة معنوية بين آراء عينة الدراسة حول

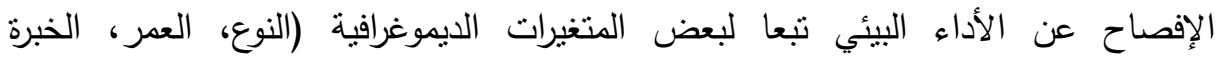
الوظيفية).

ولاختبار صحة هذه الفرضية تم استخدام اختبار (T) في حالات العينتين المستقلتين لاختبار الفروق التي تعزى لمتغير النوع، بينما نم استخدام اختبار تحليل التباين الأحادي لاختبار الفروق التي تعزى للمتغيرات الأخرى، وفيما يلي اختبار (One way ANOVA)

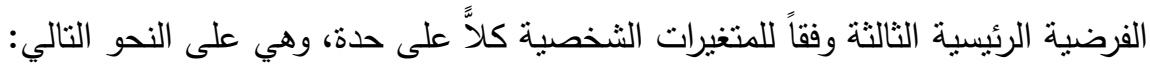
بالنسبة لمتغير النوع: قام الباحث باستخدام (Independent Samples T-test). الولاً:التنسيق مع الجهات الرقابية البيئية: لقد أظهرت النتائج عدم وجود فروق بين التين الذكور

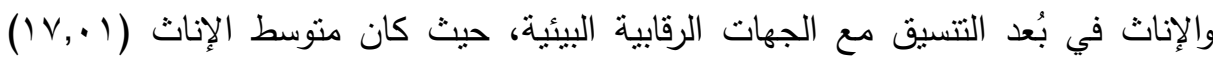

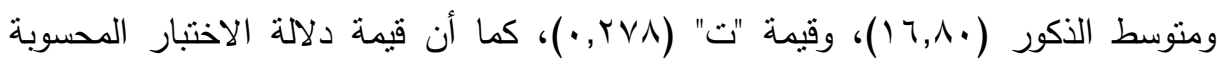

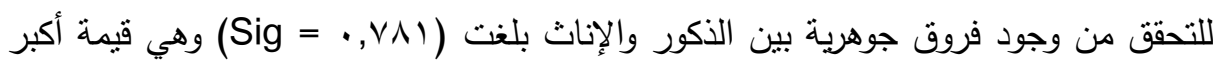
من مستوى ه.,.•، مما يعني عدم وجود فروق جوهرية ذات دلالة إحصائية بين الذكور والإناث في بُعد التتسيق مع الجهات الرقابية البيئية.

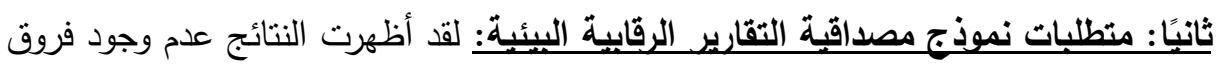
بين الذكور والإناث في بُعد منطلبات نموذج مصداقية التقارير الرقابية البيئية، حيث كان

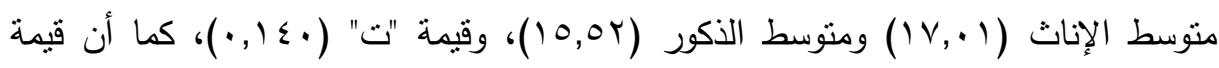

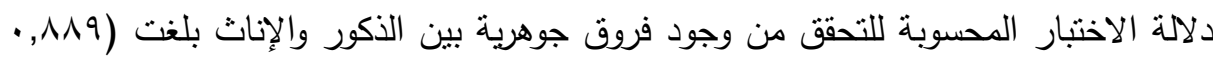

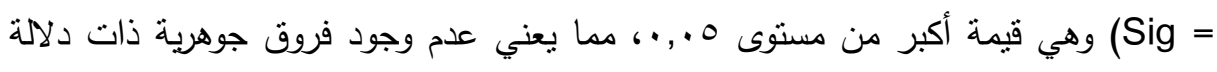

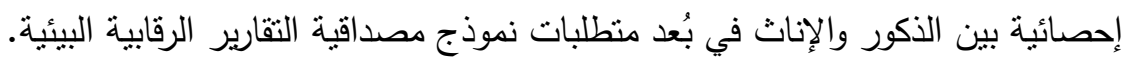

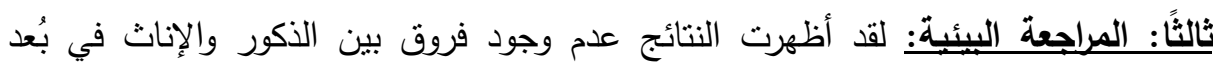

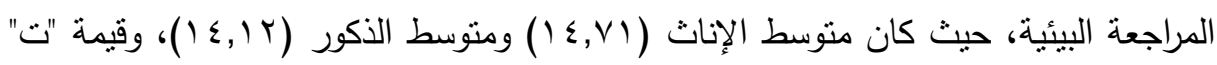

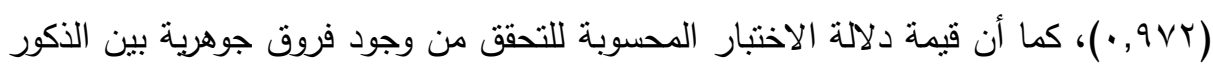

$$
\text { المجلد الخامس والأربعون، الجزء الثانى، مارس } 19 \text { بـ }
$$




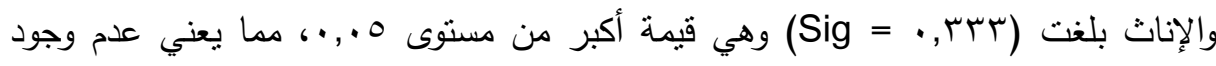

فروق جوهرية ذات دلالة إحصائية بين الذكور والإناث في بُعد المراجعة البيئية.

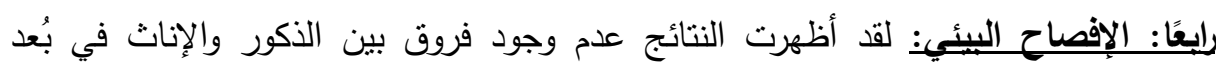

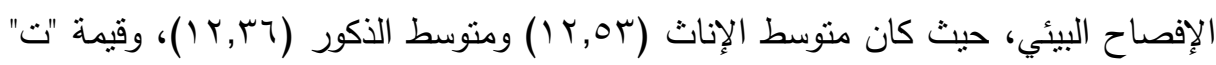

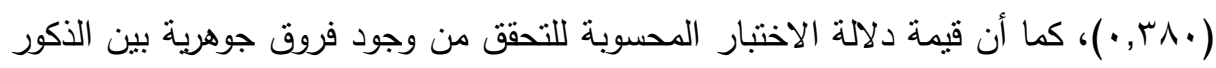

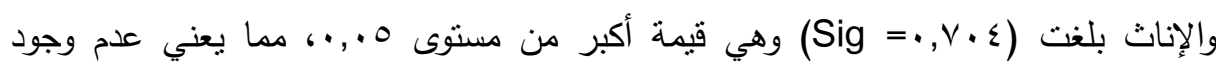
فروق جوهرية ذات دلالة إحصائية بين الذكور والإناث في بُعد الإفصاح البيئي.

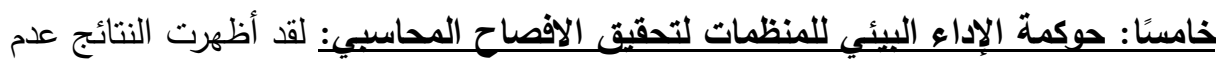
وجود فروق بين الذكور والإناث في بُعد حوكمة الإداء البيئي للمنظمات لتحقيق الافصاح

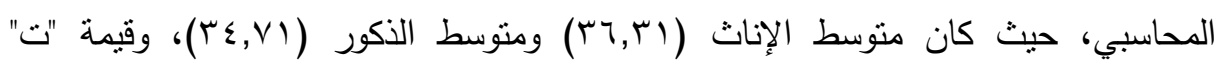

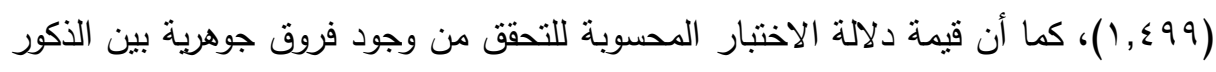

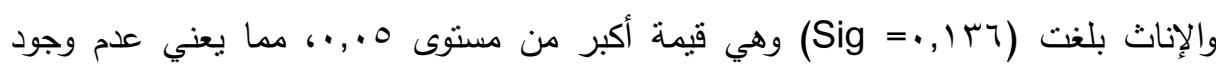
فروق جوهرية ذات دلالة إحصائية بين الذكور والإناث في بُعد حوكمة الإداء البيئي للمنظمات لتحقيق الافصاح المحاسبي. سادساً: إجمالي أبعاد الإفصاح عن الأداء اليئي: لقد أظهرت النتائج عدم وجود فروق بين الذكور والإناث في إجمالي أبعاد الإفصاح عن الأداء البيئي، حيث كان متوسط الإعاعين الإناث

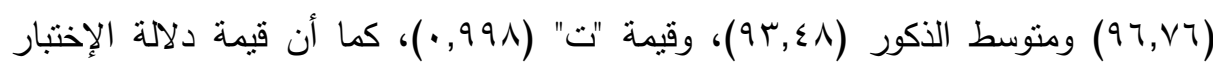

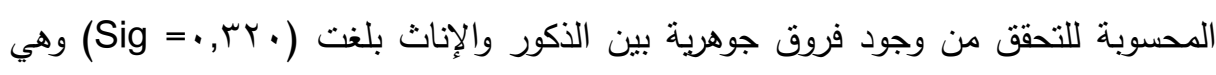

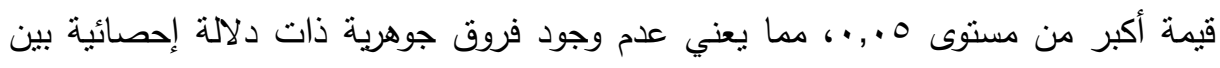

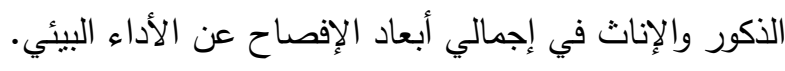

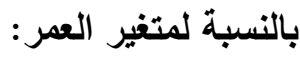

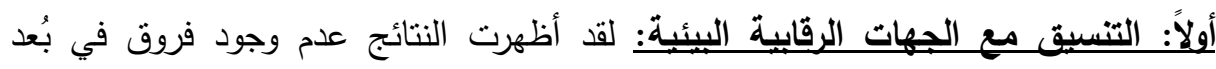
التنسيق مع الجهات الرقابية البيئية تبعاً لمتغير العمر، حيث لبئه بلغت قيمة دلالة الاختبار

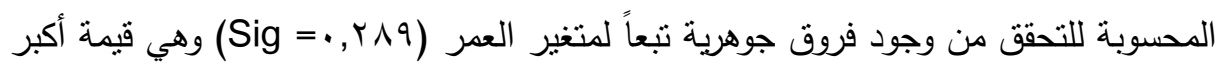


من مستوى ه.,. ،، مما يعني عدم وجود فروق جوهرية ذات دلالة إحصائية في بُعد التتسيق

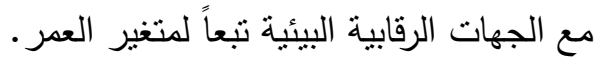
ثانبًا: متطلبات نموذج مصداقية التقارير الرقابية البيئية: لقد أظهرت النتائج عدم وجود فروق

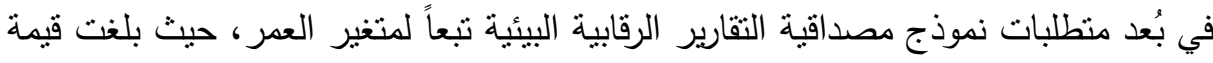

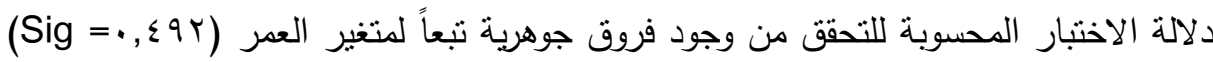

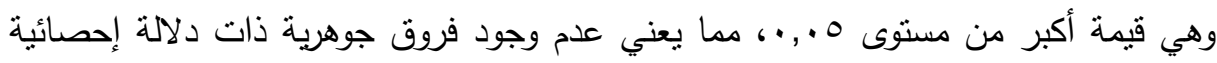

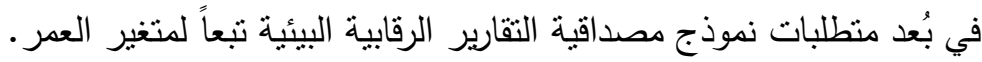
ثالثًا: المراجعة البيئية: لقد أظهرت النتائج عدم وجود فروق في بُعد المراجعة البيئية تبعاً لمتغير العمر، حيث بلغت قيمة دلالة الاختبار المحسوبة للتحقق من وجود فروق جوهرية تبعاً

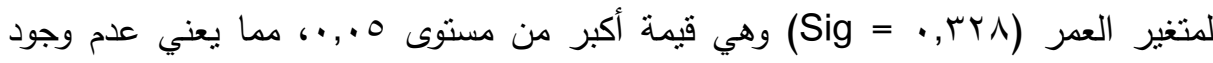

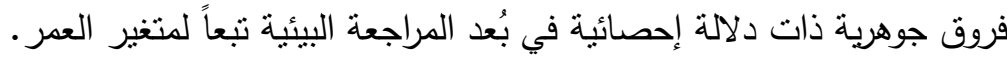

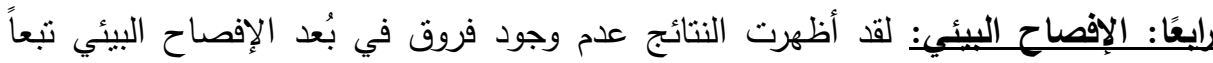
لمتغير العمر، حيث بلغت قيمة دلالة الاختبار المحسوبة للتحقق من وجود فروق جوهرية تبعاً

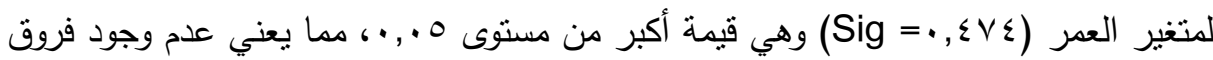

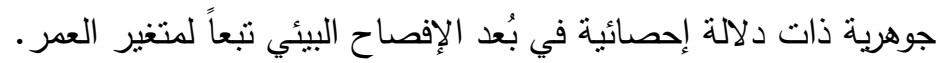
خامسيًا: حوكمة الإداء اليئي للمنظمات لتحقيق الافصاح المحاسبي: لقد أظهرت النتائج عدم وجود فروق في بُعد حوكمة الإداء البيئي للمنظمات لتحقيق الافصاح المحاسبي تبعاً لمتغير العمر ، حيث بلغت قيمة دلالة الاختبار المحسوبة للتحقق من وجود فروق جوهرية تبعاً لمتغير

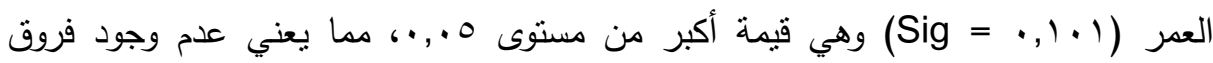
جوهرية ذات دلالة إحصائية في بُعد حوكمة الإداء البيئي للمنظمات لتحقيق الافصاح المحاسبي تبعاً لمتغير العمر . الماله

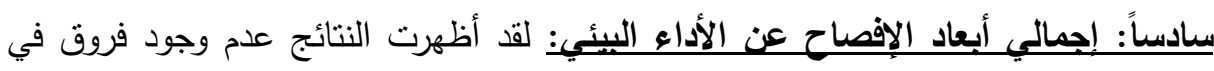
إجمالي أبعاد الإفصاح عن الأداء البيئي تبعاً لمتغير العمر ، حيث بلغت قيمة دلالة الاختبار

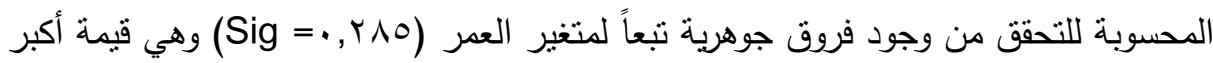

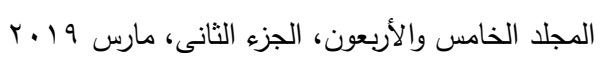


من مستوى 0 ., •، مما يعني عدم وجود فروق جوهرية ذات دلالة إحصائية إجمالي أبعاد

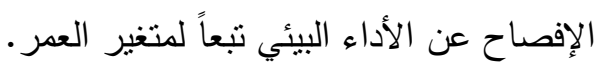

بالنسبة لمتغير الخبرة الوظيفية: قام الباحث باستخدام (One way Anova).

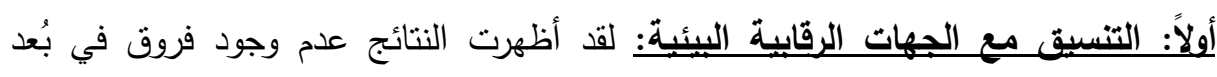

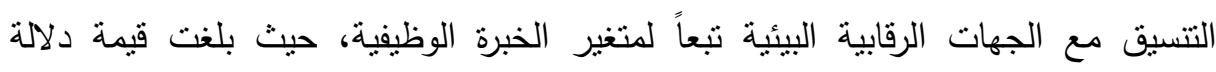
الاختبار المحسوبة للتحقق من وجود فروق جوهرية تبعاً لمتغير الخبرة الوظيفية (ع V.,..=

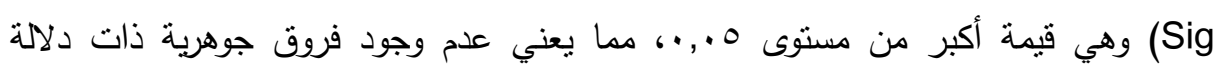
إحصائية في بُعد التتسيق مع الجهات الرقابية البيئية تبعاً لمتغير الخبرة الوظيفية.

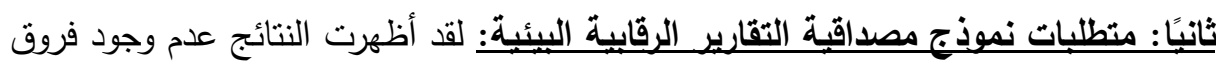
في بُعد منطلبات نموذج مصداقية النقارير الرقابية البيئية تبعاً لمتغير الخبرة الوظيفية، حيث التئية بلغت قيمة دلالة الاختبار المحسوبة للتحقق من وجود فروق جوهرية تبعاً لمتغير الخبرة

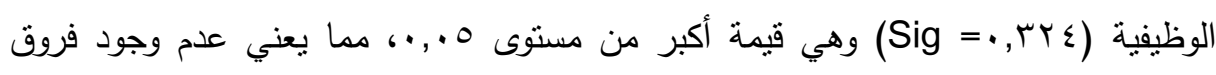
جوهرية ذات دلالة إحصائية في بُعدمنطلبات نموذج مصداقية التبر من التارير الرقابية البيئية تبعاً

الخبرة الوظيفية. ثالثًا: المراجعة البيئية: لقد أظهرت النتائج عدم وجود فروق في بُعد المراجعة|لبيئية تبعاً

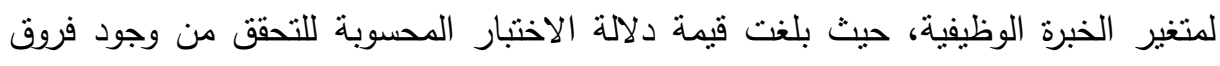

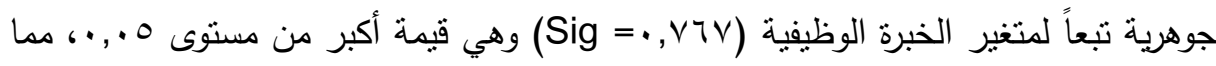
يعني عدم وجود فروق جوهرية ذات دلالة إحصائية في بُعد المراجعة البيئية تبعاً الخبرة الوظيفية. لإيعًا: الإفصاح البئي: لقد أظهرت النتائج عدم وجود فروق في بُعد الإفصاح البيئي تبعاً

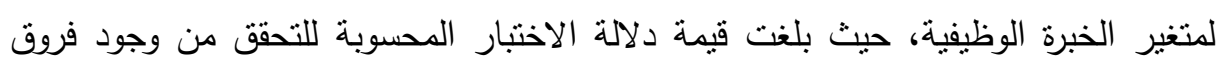

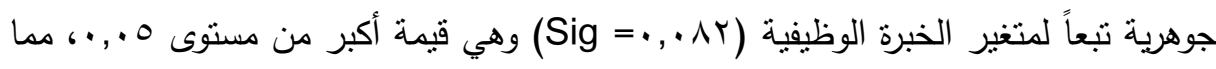
يعني عدم وجود فروق جوهرية ذات دلالة إحصائية في بُعد الإفصاح البيئي تبعاً الخبرة الوظيفية. 
خامسًا: حوكمة الإداء البيئي للمنظمات لتحقيق الافصاح المحاسبي: لقد أظهرت النتائج عدم وجود فروق في بُعد حوكمة الإداء البيئي للمنظمات لتحقيق الافصاح المحاسبي تبعاً لمتغير الخبرة الوظيفية، حيث بلغت قيمة دلالة الاختبار المحسوبة للتحقق من وجود فروق جوهرية

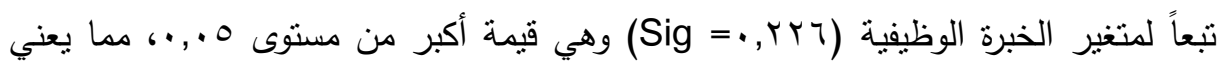

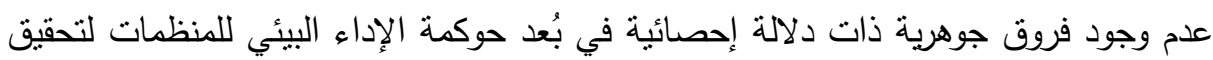
الافصاح المحاسبي تبعاً الخبرة الوظيفية.

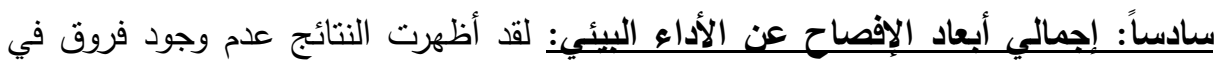

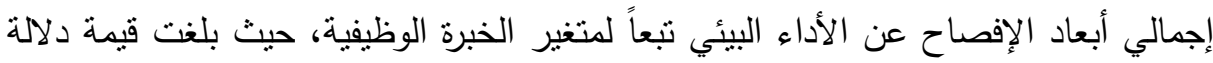
الاختبار المحسوبة للتحقق من وجود فروق جوهرية تبعاً لمتغير الخبرة الوظيفية (10 •,.

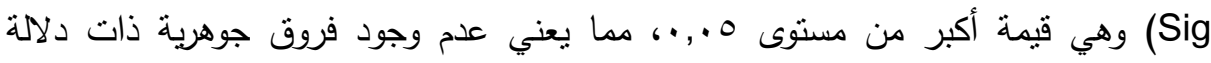
إحصائية إجمالي أبعاد الإفصاح عن الأداء البيئي تبعاً لمتغير الخبرة الوظيفية.

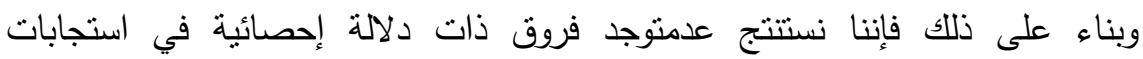
المستقصي منهم حول أبعاد الإفصاح عن الأداء البيئي تبعاً لمتغيرات (النوع، العمر، الخبرة (الوظيفية). الفرضية الرئيسية الرابعة: نوجد فروق ذات دلالة إحصائية في استجابات المستقصي منهر حول مصداقية التقارير تبعا لبعض المتغيرات الديموغرافية (النوع، العمر، الخبرة الوظبفية). ولاختبار صحة هذه الفرضية نم استخدام اختبار (T) في حالات العينتين المسنقلتين لاختبار

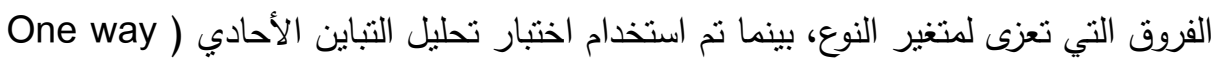
(ANOVA

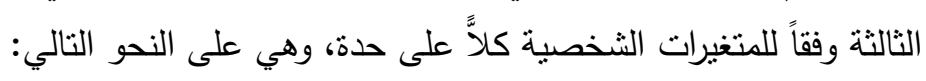
بالنسبة لمتغير النوع: قام الباحث باستخدام (Independent Samples T-test).

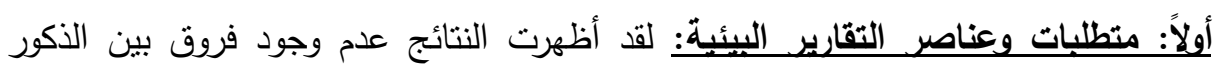
والإناث في بُعد متطلبات وعناصر التقارير البيئية، حيث كان منوسط الإناث (YV, (T)

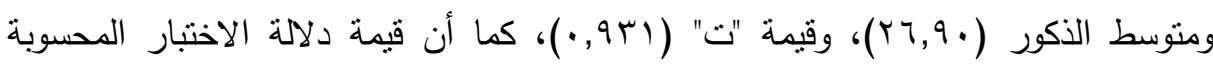

$$
\text { المجلد الخامس والأربعون، الجزء الثانى، مارس } 19 \text { بـ }
$$


للتحقق من وجود فروق جوهرية بين الذكور والإناث بلغت (ror = Sig) وهي قيمة أكبر من مستوى ه.,.•، مما يعني عدم وجود فروق جوهرية ذات دلالة إحصائية بين الذكور والإناث في بُعد منطلبات وعناصر التقارير البيئية.

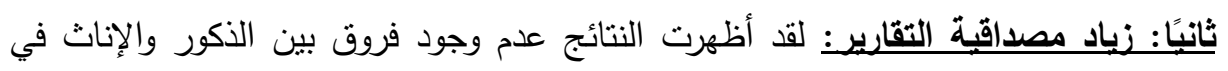

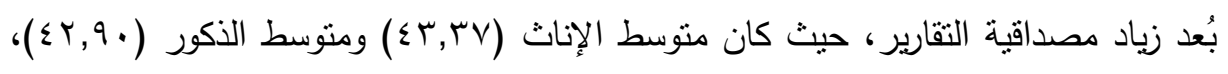

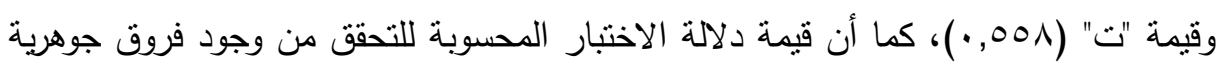

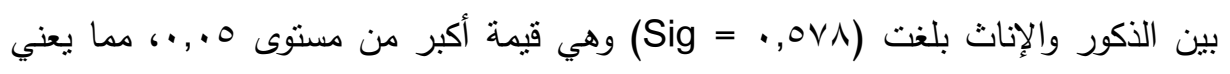

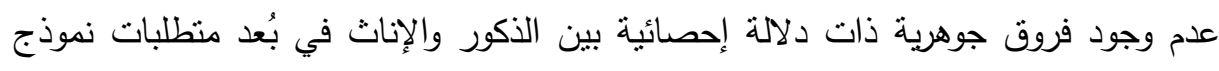

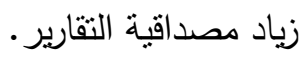
ثالثاً: إجمالي أبعاد مصداقبة التقارير: لقد أظهرت النتائج عدم وجود فروق بين الذكور

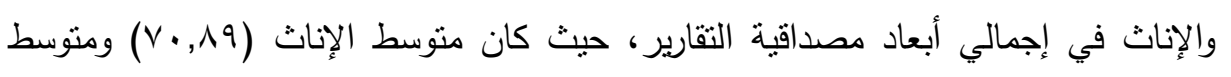

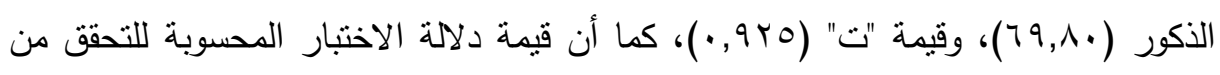

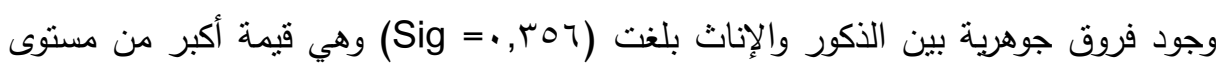

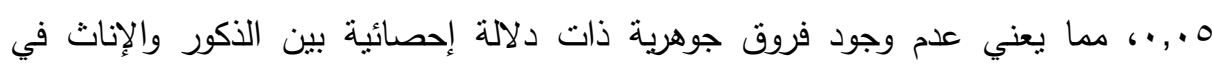

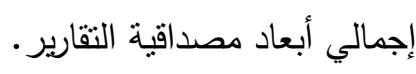

بالنسبة لمتفير العمر : قام الباحث باستخدام (One way ANOVA).

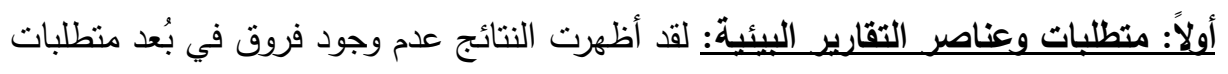

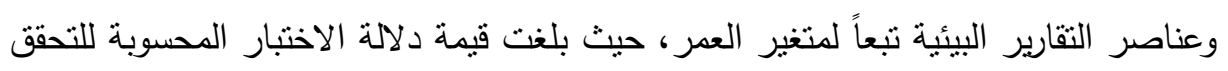

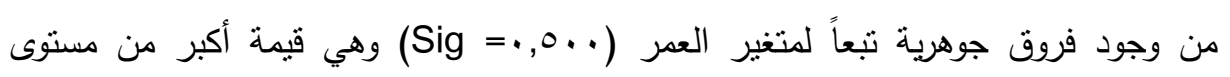

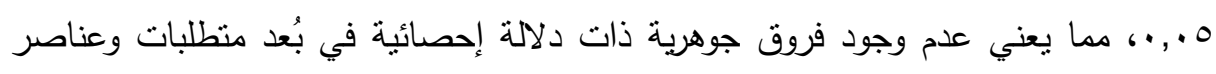

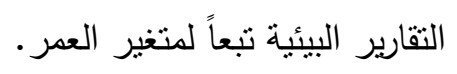
ثُانبًا: زياد مصداقية التقارير: لقد أظهرت النتائج عدم وجود فروق في بُعد زياد مصداقية

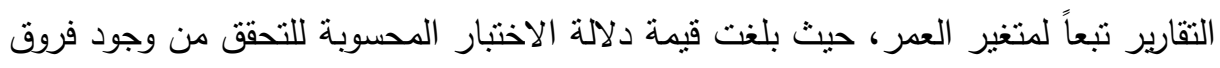

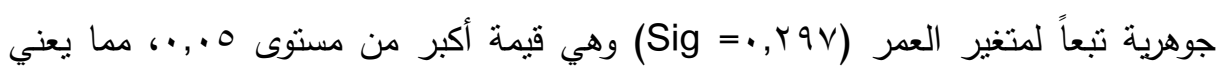


عدم وجود فروق جوهرية ذات دلالة إحصائية في بُعدزياد مصداقية التقارير تبعاً لمتغير العمر ثالثاً: إجمالي أبعاد مصداقبة التقارير: لقد أظهرت النتائج عدم وجود فروق في إجمالي أبعاد

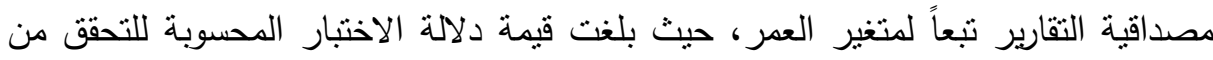

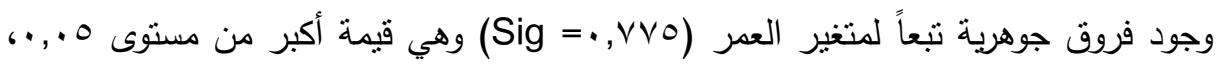
مما يعني عدم وجود فروق جوهرية ذات دلالة إحصائية إجمالي أبعاد مصداقية الثقارير تبعاً

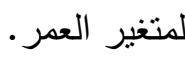

بالنسبة لمتغير الخبرة الوظيفية: قام الباحث باستخدام (Oneway Anova).

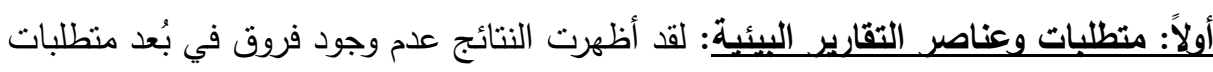
وعناصر التقارير البيئية تبعاً لمتغير الخبرة الوظيفية، حيث بلغت فيمة دلالة الاختبار

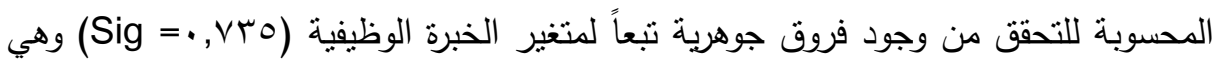

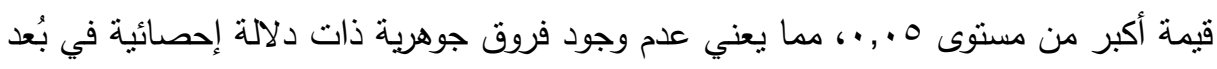

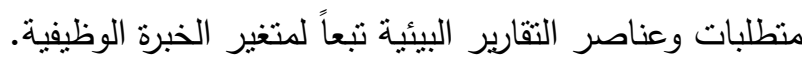

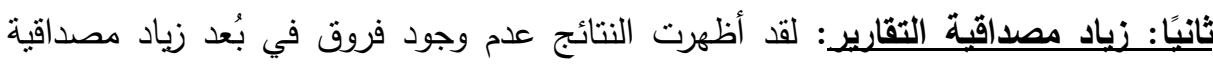

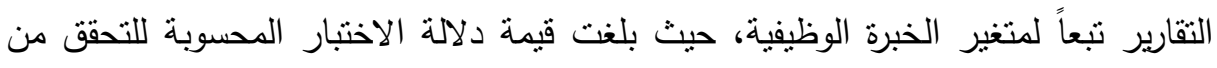

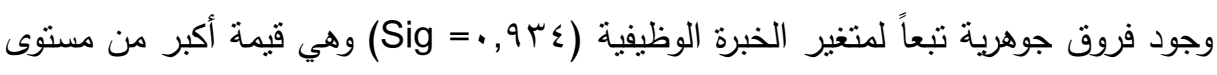
ه. , ، ، مما يعني عدم وجود فروق جوهرية ذات دلالة إحصائية في بُعدزياد مصداقية التقارير

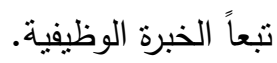
ثالثاً: إجمالي أبعاد مصداقية التقارير: لقد أظهرت النتائج عدم وجود فروق في إجمالي أبعاد

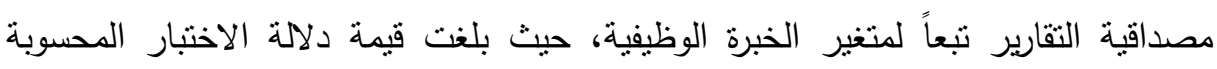

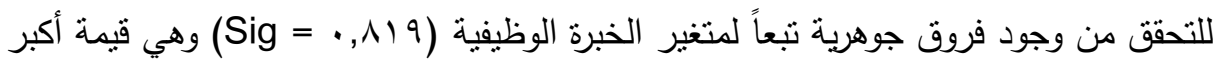
من مستوى ه., •، مما يعني عدم وجود فروق جوهرية ذات دلالة إحصائية إجمالي أبعاد مصداقية التقارير تبعاً لمتغير الخبرة الوظيفية. 
وبناء على ذلك فإننا نستتتج عدمنواجد فروق ذات دلالة إحصائية في استجابات المستقصي منهم حول أبعاد مصداقية التقارير تبعاً لمتغيرات (النوع، العمر، الخبرة الوظيفية).

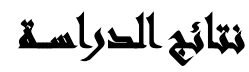

خلصت الدراسة التطبيقية الني انتهى اليها الباحث إلى أن هناك علاقة طردية مباشرة

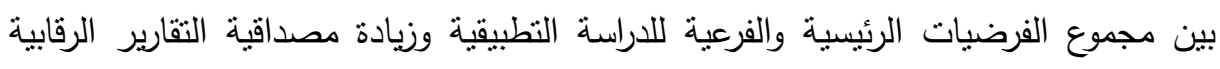

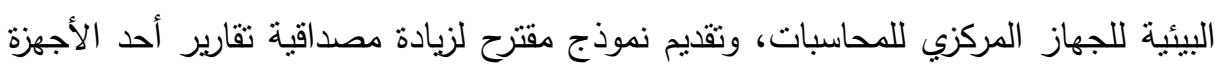
الرقابية عن الأداء البيئي للمنظمات، ونظراً لما تمثله التقارير الرقابية البيئية التي يلتزم لتئية

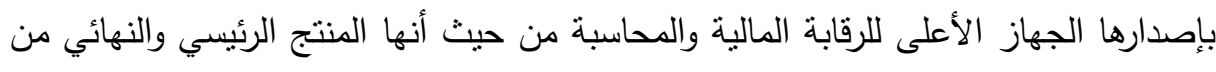
مخرجات مهام الفحص الي يقوم بها الجهاز، كونها تتضمن خلاصة الجها لإنها الرقابي البيئي

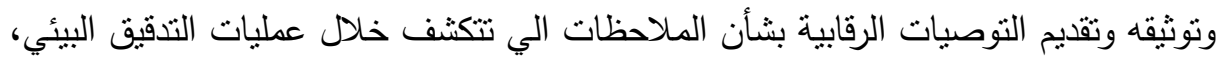

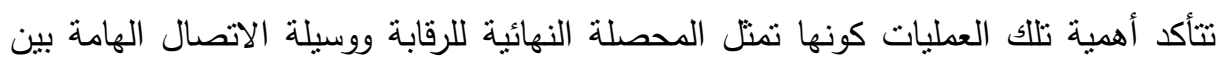
الجهاز الأعلى للرقابة وكل أولئك الذين يههم الوقوف على حقائق الأمور من مسؤولين في

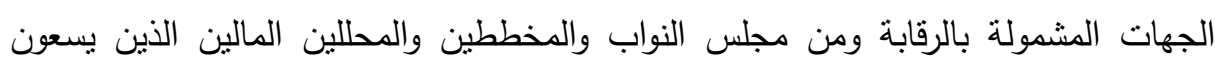
للوصول إلى البيانات الصادقة والصحيحة للاستتارة بها في صناعة القرار ووضع البع الخطط

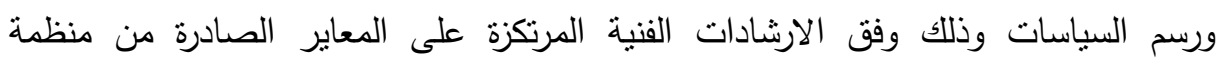

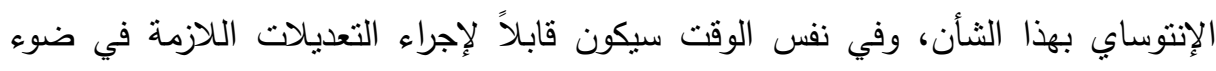

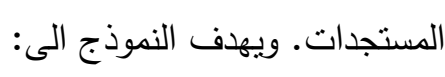
ا ـ التعريف بالتقرير الرقابي البيئي وأهدافه ومكوناته وأهمينه وأنواعه وبيان خصائص كل نوع. r. توحيد منهجية إعداد وكتابة التقارير الرقابية البيئية في الجهاز الأعلى للرقابة المالية والمحاسبة بما يتفق والمعاير الفنية الخاصة بكتابة التقرير الرقابي البيئي شكلاً ومضموناً التهاً لتعزيز مصداقيته وفق الإرشادات الصادرة عن منظمة الإنتوساي. 
r. تعريف المدققين والأعضاء الفنين بالخطوات الواجب اتباعها أثناء إعداد مسودة التقرير

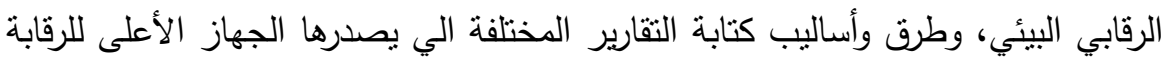

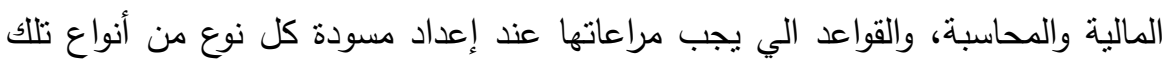

$$
\text { التقارير البيئية. }
$$

ع. تقديم إطار مبسط لكيفية استيفاء عناصر الملاحظة عند صباغة الملاحظات الي تسفر

عن تتفيذ فريق التدقيق للمهمة الرقابية البيئية المكلف بهاء

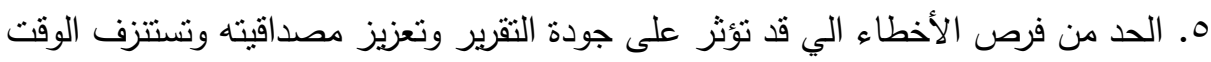
وتحول دون إبراز الجهذ المبذول أثناء تتفيذ المهمة الرقابية البيئية.

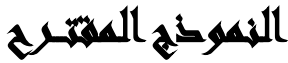

النموذج المقترح: دليل لصياغة التقارير البيئية لزيادة مصداقيتها ويحتوي على: ( ) قواعد إعداد التقارير البيئية:

1, 1, اتعريف التقرير الرقابي البيئي. r, الهدف من إعداد التقرير الرقابي البيئي.

1 r, أهمية التقارير الرقابية البيئية.

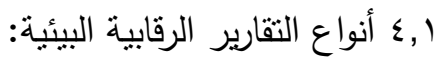
• م التقرير البيئي المبدئي

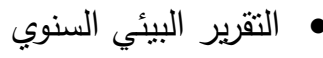

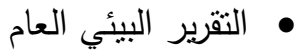
• • الثقرير البيئي الخاص

r بواعد إعداد التقارير البيئية:

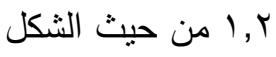
r r r r r r r من حيث المضمون 


\section{r) كتابة التقارير الرقابية ومتابعتها لتعزيز مصداقيتها:}

r, ا مسار التقارير الرقابية البيئية.

r,r r, معايير إعداد التقارير الرقابية البيئية:

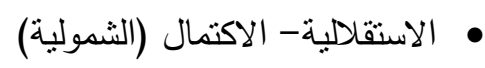

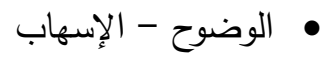

$$
\begin{aligned}
& \text { • الدقة - الموضوعية } \\
& \text { • الإقناع - التوقيت }
\end{aligned}
$$

r,r متطلبات إعداد التقارير الرقابية البيئية:

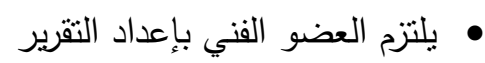
• ضضمين التقرير البيئي الخطوات المتخذة من قبل الجهاز الأعلى للرقابة والمحاسبة • التأكد من اكتمال عناصر الملاحظة وهي: ( ) (بالة (1) r r) أسباب الملاحظة البيئية ع) أثز الملاحظة البيئية 0) التوصية • هناك منطلبات خاصة بصياغة الملاحظات البيئية ضمن الثقرير الرقابي البيئي:

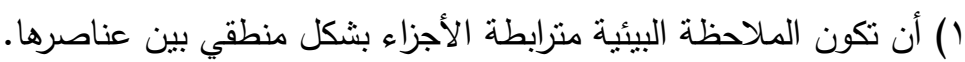

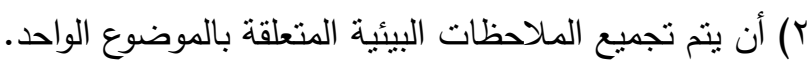

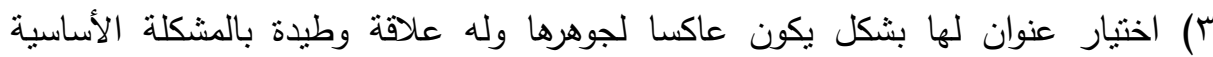

$$
\text { المرتبطة بها. }
$$

§) أن تجسد عناوين الملاحظات البيئية بشكل واضح وأن تكون معبرة عن جوهر الملاحظة

$$
\text { البيئية. }
$$

0) دعم الملاحظات البيئية بأدلة الإثبات الكافية والملائمة والمعقولة والواقعية. 7) استخدام الجمل الواضحة والسهلة والبعد عن التعقيد.

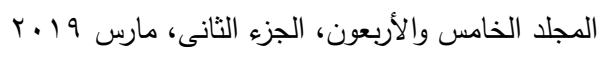


V أن تدرج البيانات التفيلية والجداول في مرفقات أو ملحقات خاصة ومعنونه ومرقمة حسب تسلسل الأرقام في الملاحظات البيئية.

^) أن تقدم الملاحظات البيئية الأكثر أهمية على الأقل أهمية. 9) الربط بن الوقائع المختلفة فقد تصل بالعضو الفني إلى اكتثاف مخالفات جسيمة وتحويلها إلى ظاهرة.

• (1) إتخاذ الإجراءات الفورية بالنسبة للوقائع الخطرة.

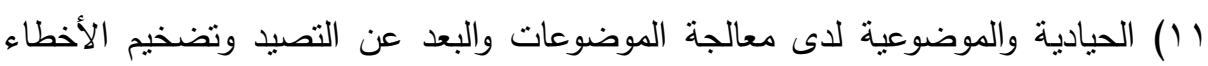
العادية التي لا نرجع إلى سوء القصد. Y T) ذكر تكلفة الأثار البيئية تقصيلاً وذلك بالتتسيق الفعال بين المدقق والعضو الفني

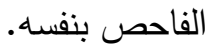
با (1) تضمن التوصيات البيئية الإجراءات التفصيلية الثارحة أوجه العلاج والتصويب اللازمة بحيث تكون معقولة وقابلة للتنفيذ وهادفة للنطوير • ب, ؟ متابعة التقارير الرقابية ونشرها: • أهداف منابعة توصيات التقارير الرقابية • وسائل متابعة توصيات التقارير الرقابية • الردود ومتابعة حالة التقرير البيئية إدراج التقرير النهائي ضمن التقرير السنوي للجهاز الأعلى للرقابة المالية والمحاسبة: ويتم ذللك بإتباع ما يلي: () إعداد التقارير البيئية النهائية المخصصة للنشر - تعديلات من حيث الثنكل. - تعديلات من حيث المضمون. r) مراجعة التقارير البيئية المخصصة للنشر على مستوى الإدارة المختصة.

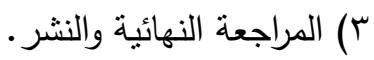




\section{توسيامي التراســا}

أولاً: الالتزام بدعم ودمج المراجعة البيئية في أعمال الأجهزة العليا للرقابة. ثاتياً: استهداف الأجهزة العليا للرقابة من المراجعة البيئية أولوية استراتيجية.

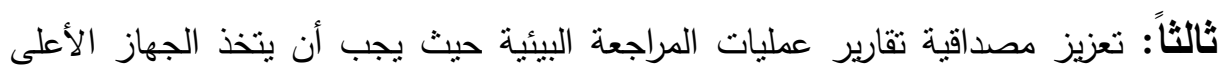
للرقابة. العديد من الإجراءات لتأكيد أن نتائج عمليات مراجعته يمكن فهمها بوضوح منل :

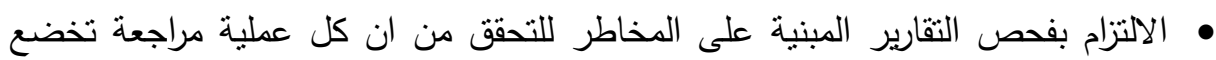
للقدر المناسب من الفحص لتأكيد أن نتائج المراجعة يمكن تدعيمها وتقديمها بأقناع. • العمل على إلزام الحكومة بالتعليق على كل عمليات المراجعة البيئية للمساعدة في تأكيد

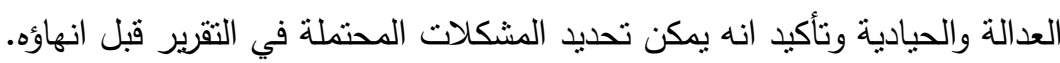
رابعاً: التتسيق بين الأجهزة العليا للرقابة والمنظمات البيئية غير الحكومية للعمل معاً. خامساً: تفعيل دور الأجهزة العليا للرقابة في مراجعة الاتفاقيات البيئية الدولية. سادساً: مشاركة الأجهزة العليا للرقابة فى التحقق من جوانب التتمية المستدامة. سابعاً: تحديد المنهج الذي يجب أن يستخدمه الجهاز الأعلى للرقابة عند مراجعة التصرفات الحكومية في مجال البيئة. ثامناً: إعادة هيكلة الجهاز الأعلى للرقابة المالية والمحاسبة واستحداث قطاع المراجعة البيئية. تاسعاً: استخدام الوسائط التكنولوجية لسرعة التواصل مع كافة الجهات ذات الصلة. عاشراً: تدريس مادة الدحاسبة والمراجعة البيئية بالجامعات والمعاهد العليا التجارية والنظم

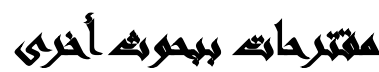

- انعكاسات ممارسة المراجعة البيئية على الجهاز الأعلى للرقابة المالية والمحاسبة. - اتجاهات الجهاز الأعلى للرقابة المالية والمحاسبة لمراقبة حوكمة البيئة المحلية.

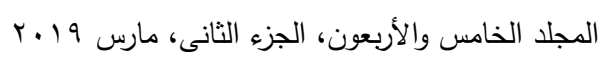




\section{2all}

أحمد بله أحمد علي (1 ( • ؟): المحاسبة البيئية ودورها في زيادة شفافية التقارير المالية، بحث تكميلي لنيل درجة الماجستير في المحاسبة، جامعة النيلين.

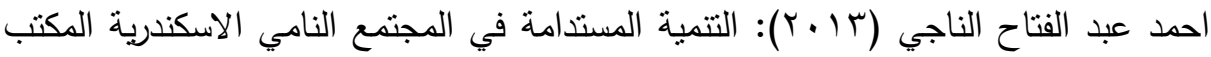

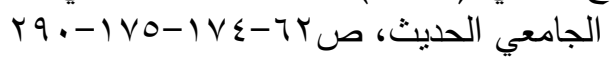

البنك الدولي "المشروع الاقليمي لإدارة النفايات الصلبة-الدلائل الاقليمية" دراسة 7 حالات الات

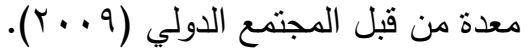

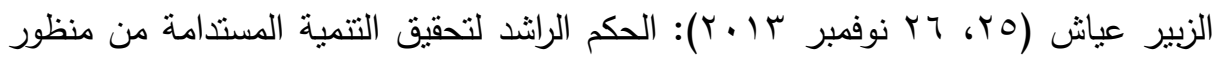

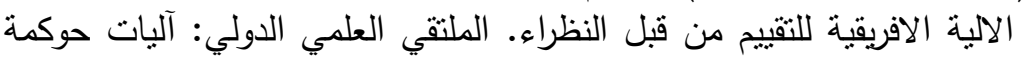

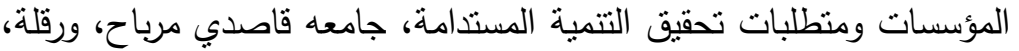

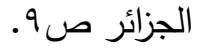

بوعلام ولهى: افاق تطبيق استراتيجية المالية الخضراء في ظل الدور الجديد للاولة مع الاشارة

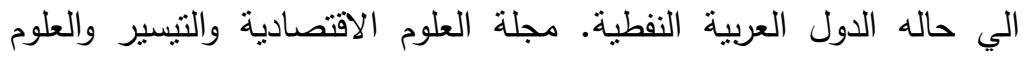

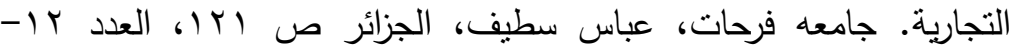

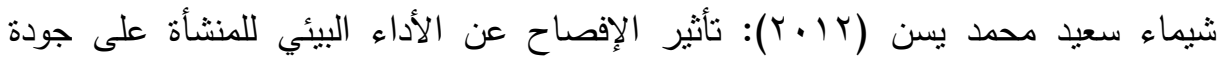

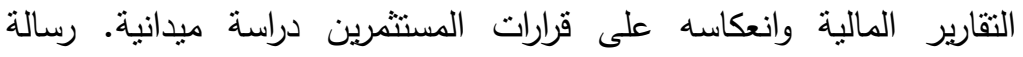

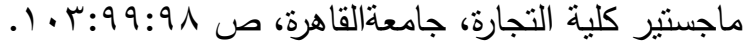

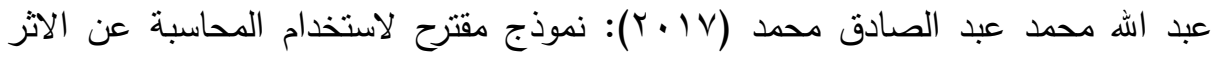

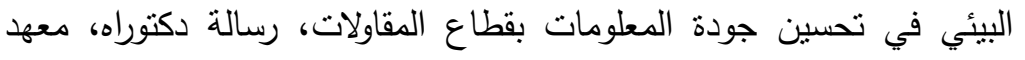
الدراسات والبحوث البيئية جامعة عين شمس.

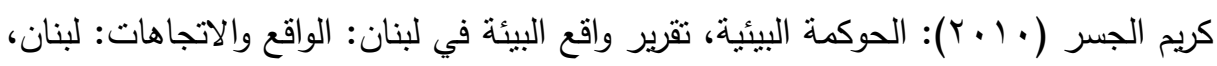
ص

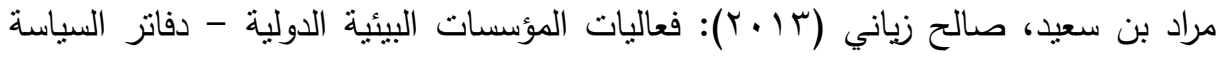

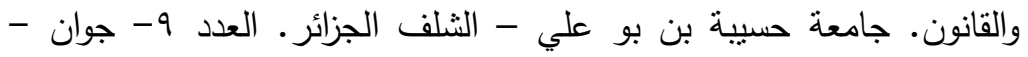
ص سr 
نادية راضي عبد الحليم: مساهمة النظم المحاسبية في التقرير والإفصاح عن الأداء البيئي

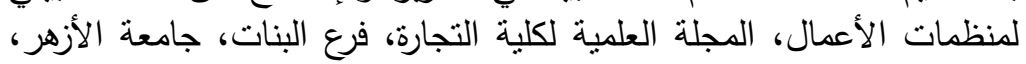

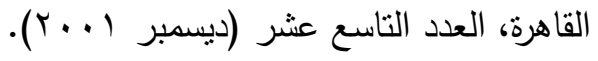

Barri, L. L.: Environmental initiatives and earnings management, Managerial Auditing Journal, Vol. 29, No: 1, pp: 76-106 (2014)

Changes (2007): The case of Egypt Review Article, Advance international accounting, vol 20, p. 75-104.

Craig Deegan (2009): Financial Accounting theory, MC-Graw Hill, hnc, P. 282

Erwan, G.; Ciban, C. and others (2014): Applicability of the frame of Reference approach for environmental monitoring of offshore renewable energy projects', Journal of Environmental Management, PP 16-28.

Minga, N. (2012): IFRS and environmental accounting' Management research review Vol. 35, No. 7. pp.,577-601.

G. Oates and A.Moradi - Motlagh (2016): is Vountary disclosure of environment performance associatd with actual environment performance? Evidence form Vioctorain Local Government, Austraili. Australuan

Orddvar, M.; Kristin, F. and others: Development of environmental performance indicators supported by an environmental information system. Application to the Norwegian defence sector' Journal of Ecological Indictors. Vol. 29, pp: 296306, (2014)

Saliem Fakir; Anthea, Stephns and Environmental Governance: (Background Research paper Environmental Govenance south Africa Environment Outlook) National state of Environmental Govemance. P. 5, (2008) 
مجلة العلوم البيئية

معهد الدراسات والبحوث البيئية - جامعة عين شمس لئس

\title{
A PROPOSAL TO ENHANCE THE CREDIBILITY OF SUPREME MONITORING AUTHORITIES OF ORGANIZATIONS ENVIRONMENTAL PERFORMANCE
}

\author{
Ahmed M. Z. A. El Khawas ${ }^{(1)}$; Mohamed A. Khalifa ${ }^{(2)}$ \\ and Salah H. Salam ${ }^{(2)}$
}

1) Institute of Environmental Studies and Research, Ain Shams University 2) Faculty of Commerce, Ain Shams University

\begin{abstract}
The application of the concepts of sustainable development, environmental impact assessment and environmental management system has had a significant impact on the increased demand for data and information resulting from the application of environmental accounting systems. This requires the review of such systems and the issuance of reports which provide users of financial statements with information to help them make informed rationale environmental decisions and to assist in terms of the controlling, planning and monitoring environmental activities. Environmental review reports reveal the level of compliance of organizations with environmental policies and laws, protecting the environment from pollution and hazards, and avoidance of overuse of natural resources to achieve sustainable development and gain competitive advantages in addition to gaining competitive advantages, tax exemptions and avoiding penalties for non-compliance with environmental laws.

The study illustrates that the enhanced credibility of reports support how Central Auditing Organization (CAO) seeks to play a vital and evolving role in promoting effective environmental governance with an objective to regulate public and private behavior towards more accountability and responsibility for preserving the environment. All

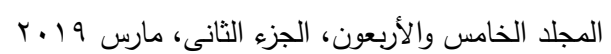


أحمد محمد زكريا عدلي الخواص وآخرون

environmental audit results help the government achieve its environmental objectives towards sustainable development. CAO plays has an important role to play in ensuring that our governments are accountable, responsible and responsive to ensure that environmental sustainability issues are at the heart of targeted development initiatives to be achieved. In order to achieve the objective of the study and to test its hypotheses, the researcher adopted the analytical descriptive methodology and field studies to collect the necessary information and required data in order to complete the study.

The study sample consisted of Exploratory Sample: This exploratory survey was performed on a sample, which consists of 40 individuals to answer 40 questionnaires, which were all submitted upon completion, in order to verify the validity and consistency of the questionnaire. And Actual Sample: After verifying the accuracy and consistency of the measurement instrument, the questionnaire was distributed to the sample comprising of 200 forms, whereas the retrieved ones were 178 forms, 18 of which are not valid for statistical analysis. Hence, the actual sample consists of 160 forms.

The study tool was designed based on initial identification of the of the measure phrases used in accordance with the study topic, its objectives and questions, after detailed readings, literature review and consideration of previous studies related to the problem of study and the researcher's experience. The study tool consists of: Part 1: includes personal data. Part 2: includes special phrases for environmental performance disclosure which includes 40 phrases divided into five dimensions. Part 3: includes the statements related to the credibility of the reports which includes 26 phrases divided into two dimensions. For validation purposes, we can measure the psychometric characteristics of this tool which are represented in honesty and consistency. The study objective can be achieved by proposing a model to enhance the credibility of the reports of the CAO on environmental performance of organizations in order to achieve a set of secondary objectives, e.g. development of standards, baselines, guidelines for developing environmental audit reports, ensuring the adequacy of environmental management systems in the organization and their actual compliance with environmental laws and legislative and safety requirements to

$$
\text { المجلد الخامس والأربعون، الجزء الثانى، مارس } 19 \text { ـ ا ب }
$$


reduce the exposure to environmental hazards in addition to the assessment of effectiveness of existing environmental management systems, provide consultation to the administration with regards to possible improvements of such systems in order to achieve environmental enhancement, ensure the accuracy and validity of financial statements related to environmental performance of the organization which is recorded in the accounting and non-accounting records and registers and any other reports related to environmental performance, ensure the validity of presented data and disclosure of any liabilities or possible losses resulting from environmental issues in the financial statements and annexes thereto for the audited organization. This research also sheds some light on environmental accounting, issues of environmental accounting measurement and submitting proposals thereto, in addition to the methodology to achieve a documented environmental audit process to identify subjective evidence, which match environmental measures to provide and disclose appropriate information and data, which have an impact on financial statements and related reports to enhance their credibility. By analyzing the model of enhancing credibility, all variables lead to increased credibility in the reports issued by the Authority.

In addition to the findings identified by the researcher in evaluating previous studies including the commitment to support and integrate environmental auditing in the work of senior auditing authorities, the study recommends the following:

Identify the methodology, which CAO should use when auditing government actions in the field of the environment, restructuring CAO and developing the environmental audit sector, participation and coordination between $\mathrm{CAO}$ in terms of verifying aspects of sustainable development, focusing CAO strategy on environmental auditing as a strategic priority, and activate the role of $\mathrm{CAO}$ in reviewing international environmental agreements.

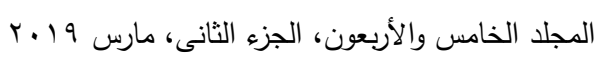

